\title{
AVALIAÇÃO DO VALOR TURÍSTICO-EDUCACIONAL E RELEVÂNCIA DOS GEOSSÍTIOS CÁRSTICOS DO PARQUE ESTADUAL INTERVALES (SP)
}

\author{
EVALUATION OF THE TOURISM-EDUCATIONAL VALUE AND RELEVANCE OF THE KARST \\ GEOSITES OF THE INTERVALES STATE PARK (SÃO PAULO STATE, BRAZIL)
}

Túlio César Rocha CAMARgo, Heros Augusto SANTOS LOBO

Universidade Federal de São Carlos, campus Sorocaba. Rodovia João Leme dos Santos, (SP-264), Km 110, s/n - Itinga, Sorocaba SP. E-mails: tulio.camargo@etec.sp.gov.br; heroslobo@ufscar.br

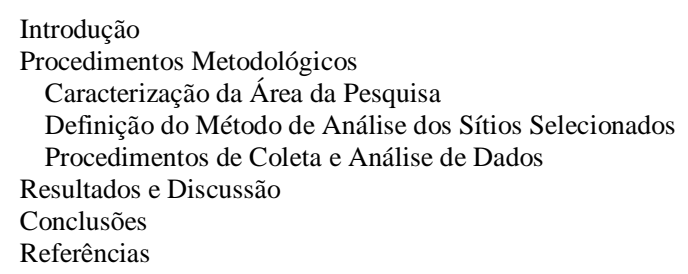

RESUMO - Os elementos naturais mais relevantes devem ser alvo de ações de conservação, tais como a criação de áreas naturais protegidas, ou mesmo de ampliação de seu conhecimento com o uso de estratégias de inventário, entre outras. Neste contexto, foi realizada a classificação dos geossítios cársticos do Parque Estadual Intervales. Para tanto, foram utilizados métodos para a análise de geossítios em áreas cársticas, com a inclusão do Valor de Uso Turístico-Educacional (VUTE), em função da realidade de uso público da área pesquisada. Os resultados demonstraram a categorização dos geossítios nos valores: intrínseco, científico, turístico, uso/gestão e educacional. Por fim, os geossítios foram comparados com o uso dos rankings de Relevância Tradicional (RT) e do novo modelo Proposto (RP), com a identificação de 10 geossítios de relevância nacional na região. Conclui-se que tais geossítios devem receber estratégias formais de geoconservação como apoio à sua proteção e uso sustentáveis, tais como: desenvolvimento de material interpretativo específico; descrição formal dos geossítios em inventários vigentes; e a possibilidade de inclusão dos geossítios mais relevantes na proposta de Geoparque existente para o Alto Ribeira.

Palavras-chave: Unidade de Conservação; Geoconservação; Geodiversidade; Valor de Uso Educacional.

\begin{abstract}
The most relevant natural elements should be the subject of conservation actions, such as the creation of protected natural areas, or even the expansion of their knowledge with the use of inventory strategies, among others. In this context, the classification of karst geosites in the Intervales State Park was carried out.. For this, adapted methods were used for the analysis of geosites in karst areas, with the inclusion of Educational Tourism Use Value (VUTE), as a function of the reality of public use of the area. The results showed the categorization of the geosites in the values: intrinsic, scientific, tourist, use/management and educational. Finally, the geosites were compared with the use of the rankings of Traditional Relevance (RT) and the new Proposed model (RP), with the identification of 10 geosites of national relevance in the region. It is concluded that such geosites should be subject to formal geoconservation strategies in support of their sustainable protection and use, such as: development of specific interpretive material; formal description of geosites in current inventories; and the possibility of including the most relevant geosites in the existing Geopark proposal for the Upper Ribeira.
\end{abstract}

Keywords: Natural Protected Areas; Geoconservation; Geodiversity; Educational Use Value.

\section{INTRODUÇÃO}

No âmbito da conservação da natureza, o enfoque de grande parte dos estudos atuais é centrado em questões biológicas, destacando a fauna e a flora (Brilha, 2005; Nurit, 2006; Neiman, 2007). Nos últimos anos, uma nova forma de analisar o ambiente aponta para o meio físico, o qual vem sendo estudado sob a ótica da geodiversidade (Gray, 2004) e, por consequência, a geoconservação (Sharples, 2002; Brilha, 2005). Esta abordagem sobre a paisagem considera a totalidade de seus elementos, tomando por base o meio físico, mas considerando também os meios biótico e social (Sharple, 2002).
Por outro lado, entende-se que nem todos os elementos do meio físico devem ser conservados, assim como ocorre com o meio biótico. A lógica mais adequada, que vem sendo utilizada já há décadas, é a de identificação de sítios representativos ou singulares, para que parcelas do ambiente sejam preservadas por razões intrínsecas ou por atender determinadas finalidades aos seres humanos (Araújo, 2005; Lobo \& Boggiani, 2013; Brilha, 2016; UNESCO, 2017). Em âmbito universal, tais sítios de maior relevância ou significado podem vir a ser classificados como Patrimônios da Humanidade, cujo selo é concedido pela UNESCO nas 
categorias Natural, Cultural ou Misto (UNESCO, 2017). Para além destas categorias, pode-se fazer desdobramentos temáticos conforme interesse e conveniência técnica ou legal, resultando em tipologias de patrimônio como Geológico (CPRM, 1997), Paleontológico (BRASIL, 1942) e Espeleológico (CONAMA, 2004), entre outros. No entanto, é importante ressaltar que tais subdivisões são relativamente artificiais, pois observam um dos enfoques de um sítio natural, isolando-o, por vezes, de seu contexto mais amplo (Lobo et al., 2016). Assim, independente do enfoque específico, devem ser desenvolvidos estudos e ações que promovam a geoconservação em consonância com as tendências atuais de conservação da natureza de um modo geral, as quais podem ser observadas em IUCN (1948) e UNESCO (2018), entre outros trabalhos.

Consoante à esta abordagem, uma das principais estratégias para a geoconservação na atualidade é o inventário e classificação da geodiversidade, buscando encontrar seus sítios mais relevantes, denominados geossítios (Brilha, 2005). Por questões estratégicas e práticas, esta análise vem sendo feita em porções definidas do território, tais como municípios, regiões ou mesmo áreas naturais protegidas. No Estado de São Paulo, um detalhado levantamento vem sendo conduzido, com resultados parciais já publicados (Garcia et al., 2017). Contribuindo com este inventário, o presente trabalho é fruto de uma pesquisa que se debruçou sobre a análise dos sítios cársticos do Parque Estadual Intervales (PEI), uma Unidade de Conservação amplamente utilizada para fins turísticos e científicos. A área é notoriamente conhecida por conservar parcelas representativas da Floresta Atlântica, bem como por áreas de relevo cárstico (Fundação Florestal, 2008). No entanto, existe uma lacuna em relação ao detalhamento dos sítios naturais do meio físico nas bases atuais de análise, definidas por métodos de inventário, quantificação e valoração, tal como se observa em seu Plano de Manejo (2008) e nos Planos de Manejo Espeleológico de algumas de suas cavernas (2010). Embora seja uma área já protegida por uma Unidade de Conservação, tais estudos são importantes tanto para endossar a relevância dos sítios já protegidos quanto para obter novas possíveis abordagens de utilização daqueles em que o uso público é permitido.

Nos estudos similares já realizados anteriormente no Brasil, como por exemplo, na Chapada Diamantina (Pereira, 2010) e no PETAR (Ferreira, 2014), os pontos de interesse foram analisados com o uso de critérios de valoração nas categorias de Valor Intrínseco, Valor Científico, Valor Turístico e Valor de Uso/Gestão. O estudo atual utilizou as mesmas categorias, além de acrescentar a de Valor Educacional. Além disso, foram aplicados os parâmetros já existentes no Valor Científico e de Uso/Gestão e estudado o acréscimo de outro(s) parâmetro(s) para pontuação e cálculo de uma média aritmética.

Para conferir um enfoque à pesquisa realizada, o objetivo geral foi reconhecer e analisar os valores específicos dos geossítios cársticos do PEI e seu entorno imediato, contribuindo com as estratégias de uso sustentável deste patrimônio e com a geoconservação.

\section{PROCEDIMENTOS METODOLÓGICOS}

\section{Caracterização da Área da Pesquisa}

O PEI está localizado no território núcleo do Contínuo Ecológico de Paranapiacaba. Sua área total de 41.704 ha é constituída por cerca de 38.356 ha de propriedade da Fundação Florestal, e de 3.348 ha em terras devolutas. O PEI protege o segundo e mais importante corredor ecológico de Mata Atlântica do Estado de São Paulo, em conjunto com o Parque Estadual Turístico do Alto Ribeira (PETAR), Parque Estadual Nascentes do Paranapanema (PENP), Parque Estadual Carlos Botelho (PECB), a Estação Ecológica Xitué (EecX) (Figura 1).

O PEI está inserido em duas sub-regiões geográficas distintas: a sub-região do Vale do
Ribeira e a sub-região do Vale do Alto Paranapanema, abrangendo os municípios de Ribeirão Grande, Guapiara, Sete Barras, Eldorado e Iporanga e em seu limite Norte, divisa com o município de Capão Bonito. A Sede do Parque, localizada no município de Ribeirão Grande, à 270 $\mathrm{km}$ da capital (Marinho, 2008). A região da sede concentra infraestrutura administrativa, de manutenção e apoio operacional incluindo 3 pousadas, restaurante, casa da monitoria ambiental, espaços de recreação e lazer, alojamento de pesquisadores, residências funcionais. As bases do vale do Ribeira possuem alojamentos de fiscalização e um alojamento de pesquisa na base Saibadela (São Paulo, 2009). 


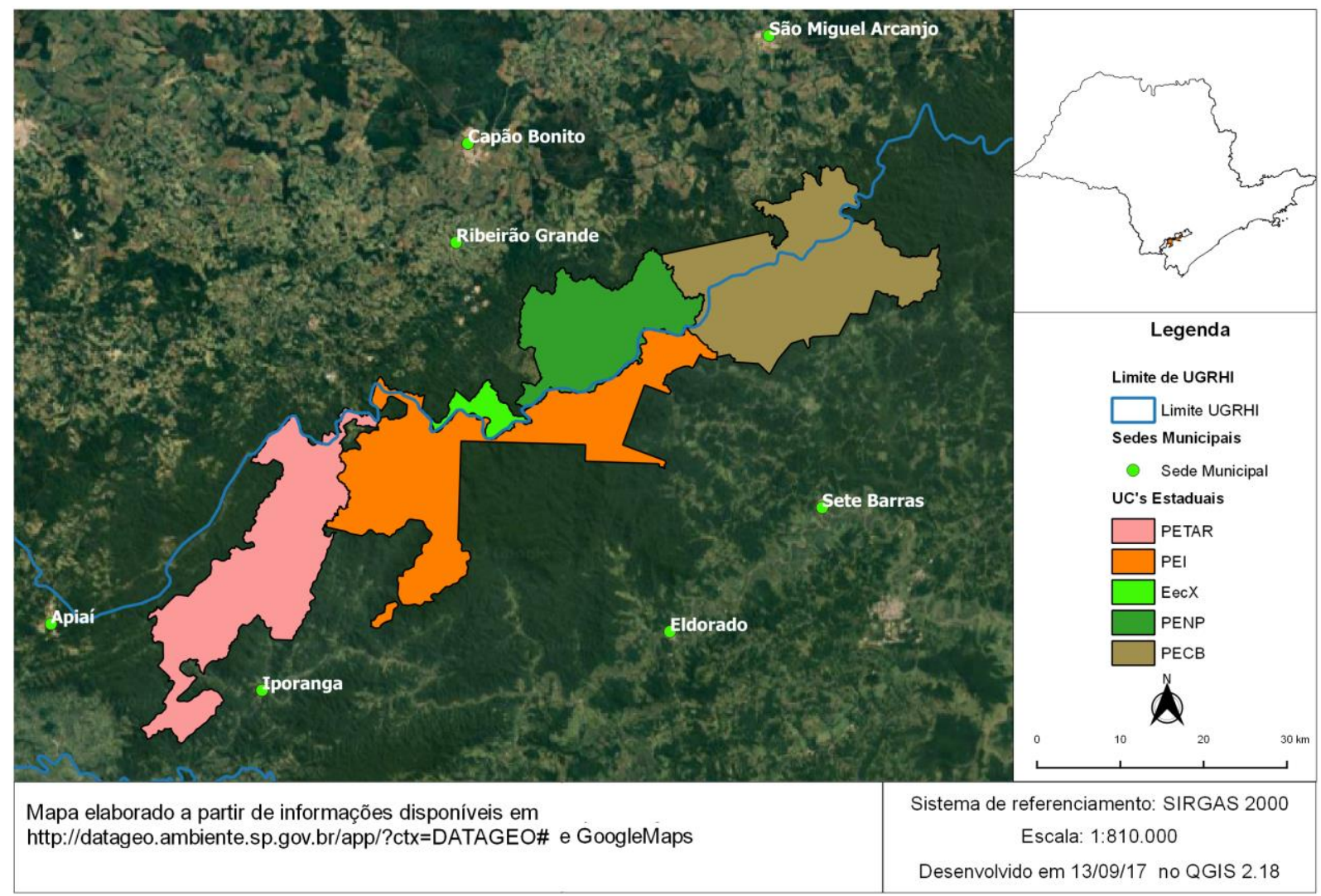

Figura 1 - Localização do PEI em relação ao Estado de são Paulo e às demais Unidades de Conservação da região.

Segundo Karmann \& Ferrari (2002), as regiões do Vale do Ribeira e Alto Paranapanema revelamse como das mais importantes áreas cársticas do mundo, devido as feições típicas, como carste poligonal, cones e cânions cársticos, vales fluviais profundos, escarpamentos rochosos com pórticos de cavernas, extensos sistemas de drenagem subterrânea com grande variedade espeleomorfológica, e cavernas com sítios paleontológicos do Quaternário. Ford \& Williams (2007) relatam que as áreas cársticas abrangem de 10 a $15 \%$ da superfície terrestre.
O clima regional subtropical é permanente úmido controlado por massas tropicais e polares marítimas (Monteiro, 1973). As variações topográficas possibilitam a diversificação de climas locais no PEI (Fundação Florestal, 2008; Fundação Florestal, 2010).

Sobre a geologia regional, segundo Theodorovicz (2014) a região do PEI é uma das mais variadas e complexas geologia do sul-sudeste do Brasil, como destaca no limite proposto de preservação do patrimônio geológico para criação de um Geoparque (Figura 2).

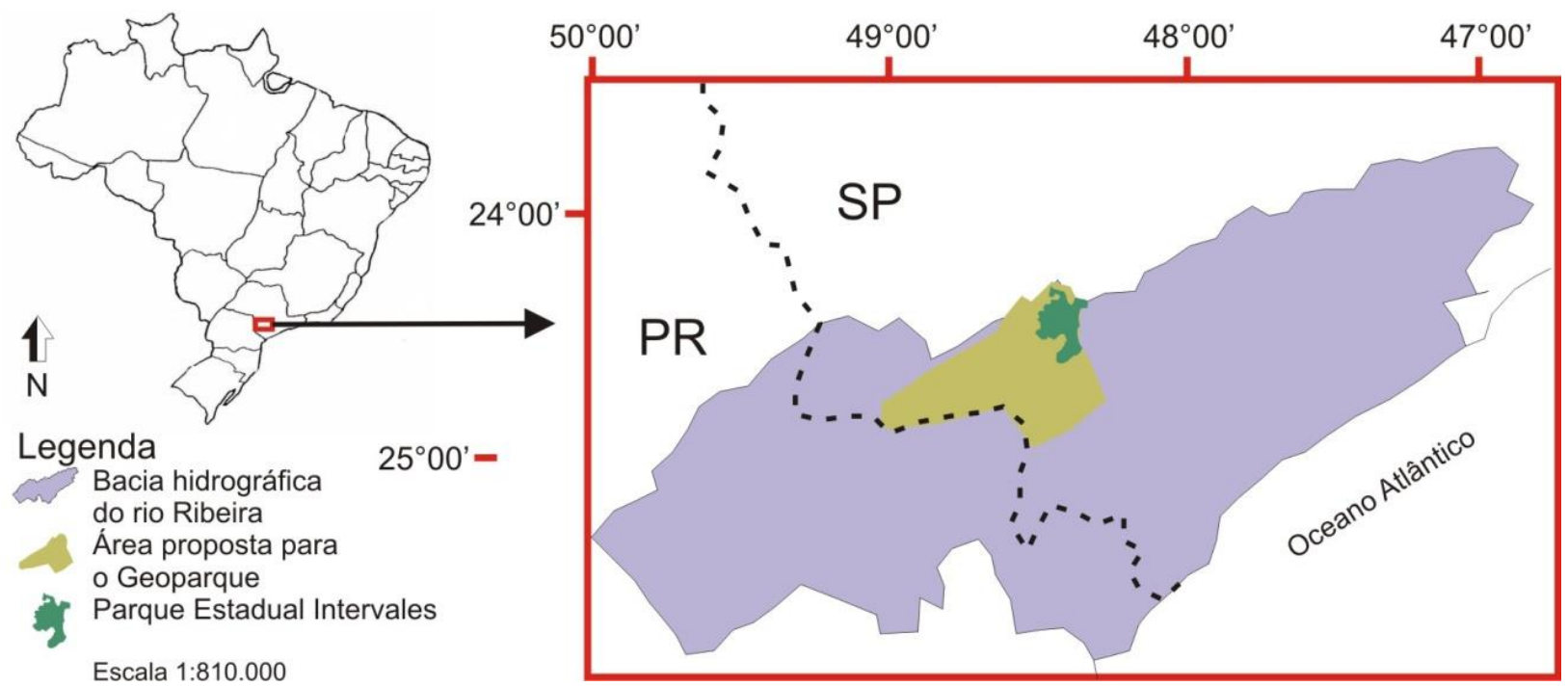

Figura 2 - Demarcação do limite proposto do Geoparque e em relação ao Parque Estadual Intervales (PEI). Fonte: Adaptado de Theodorovicz (2014). 
A área do PEI está inserida na porção central da Província Mantiqueira (Almeida, 1977), a qual é denominada por Hasui et al. (1975) como "Faixa de Dobramentos Ribeira". Segundo Campanha et al. (1987), a Faixa Ribeira é um cinturão que está recoberta pelas rochas sedimentares da Bacia do Paraná a W e a SW, limitada a NNW pelo Maciço de Guaxupé, a SSE pelo Maciço de Joinville, e para NE faz a transição para terrenos de médio a alto grau. Neste bloco, ocorre predominantemente um conjunto de rochas supracrustais, de grau metamórfico fraco a médio, denominado de Supergrupo Açungui.

Sallun \&Sallun Filho (2009) afirmam que nesse Supergrupo, há a intrusão de um grande número de corpos granitoides de características variadas em consequência ao destaque dado por Campanha \& Sadowski (1999), que evidenciam o Supergrupo Açungui composto pelas unidades geológicas do Grupo Itaiacoca, Formação Água Clara, Grupo Votuverava (Subgrupo Lajeado e Subgrupo Ribeira), Formação Capiru e Grupo Setuva.

Segundo Campanha (2002) e Sallun \& Sallun Filho (2009), a geologia regional é formada por filitos, granitóides, xistos, micaxistos e mármores (metacalcários), classificada em depósitos sedimentares cenozoicos, diques básicos jurocretáceos, granitoides (Suítes e Corpos Graníticos pós tectônicos, Complexo Três Córregos, Complexo Agudos Grandes, Corpos Graníticos, Gabro de Apiaí) e rochas metamórficas do Supergrupo Açungui (Figura 3).

O PEI está inserido em área de diversificada configuração geomorfológica, pois está localizado na transição Planalto/Serra do Mar, Serra de Paranapiacaba e baixo Ribeira, ao sul do Estado de São Paulo (Ross \& Moroz, 2011). A partir do estudo em escala de maior detalhe foi possível elaborar e propor novas denominações aos compartimentos geomorfológicos ou morfoesculturas da região do PEI e seu entorno, ou seja, três macro compartimentos da área: Planalto de Guapiara, Serra do Mar e Paranapiacaba e Depressão do Baixo Ribeira (Fundação Florestal, 2008). Quanto à espeleologia, predominam as cavernas de menor desenvolvimento e desnível, na ordem de dezenas de metros, a maioria dessas associadas às sub-bacias do rio das Almas e rio São José do Guapiara, tributários do rio Paranapanema. (São Paulo, 2009).
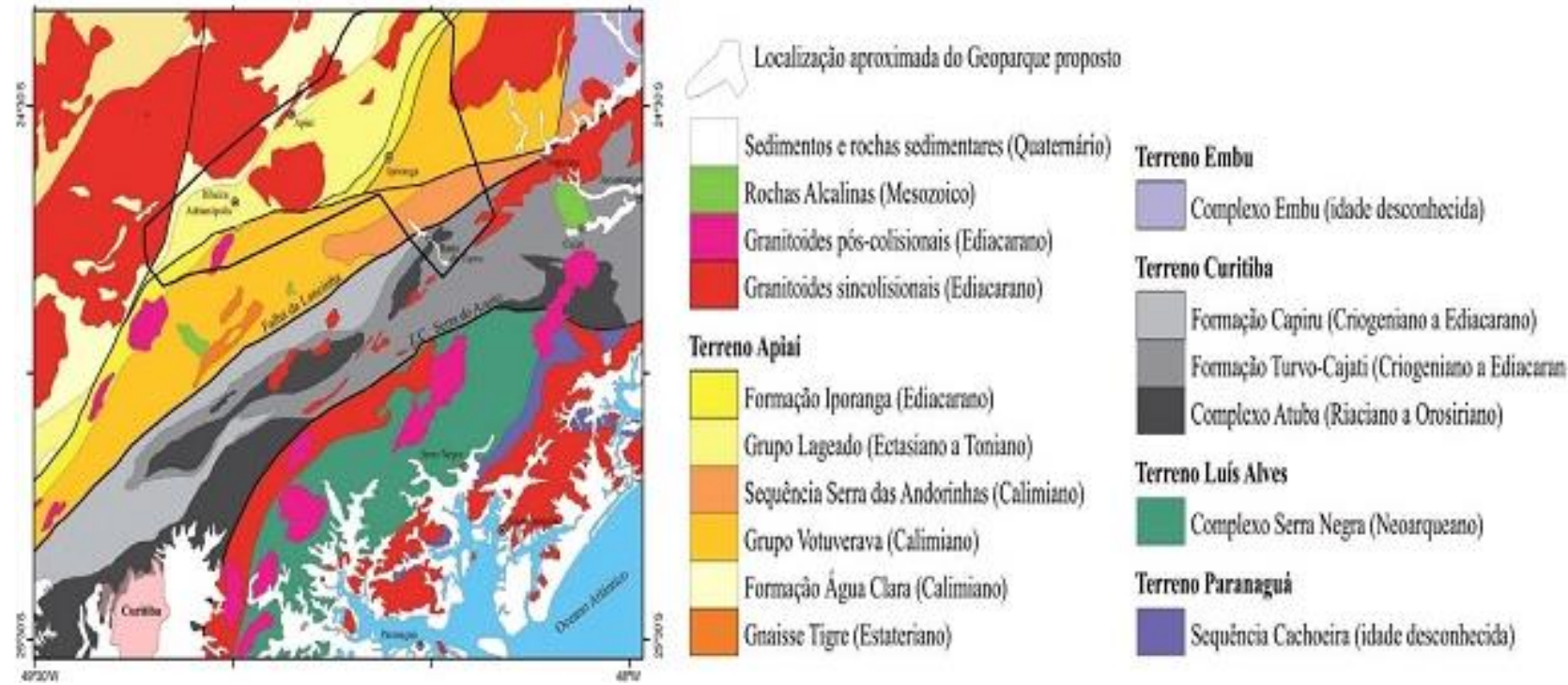

Figura 3 - Geologia regional do Parque Estadual Intervales (PEI) dentro da de marcação proposta de Geoparque a qual faz parte da Formação Iporanga, Grupo Lageado, Grupo Votuverava. Fonte: Adaptado de Faleiros et al. (2012).

O uso público turístico do PEI é desenvolvido com perspectivas ao atendimento da visitação turística recreativa e de atividades de estudos do meio e de educação ambiental. O Parque conta com a base local, administração, pousadas e guias locais. Com isso, atendem diversos perfis de visitantes, desde o que procuram aventura até o estudo. A Tabela 1 traz os dados de visitação dos últimos anos.

O total de visitantes é distribuído em 45 roteiros de visitação dentro do Parque. Destes, apenas 16 foram escolhidos para serem avaliados. Os demais não atendiam aos critérios da presente pesquisa, no que diz respeito a representarem ou evidenciarem sítios da geodiversidade. Exemplos de roteiros descartados foram aqueles desenvolvidos em trilhas em meio à floresta, sem nenhuma evidência visível de elementos da geodiversidade. Os roteiros escolhidos foram as grutas: Fendão, Mãozinha, Santa, Colorida, Jane 
Mansfield, Minotauro, Fogo, Tatu, Cipó, as cachoeiras do Mirante, Água Comprida e do Meninos, Paiva (entorno) e Luminosa (entorno); Arcão (entorno) e o mirante da Anta (Figura 4).

Tabela 1 - Evolução do número de visitantes anuais no PEI. Dados parciais em 2013. Fontes: Sistema Ambiental Paulista (2013) e dados da gestão do PEI (2014-2016).

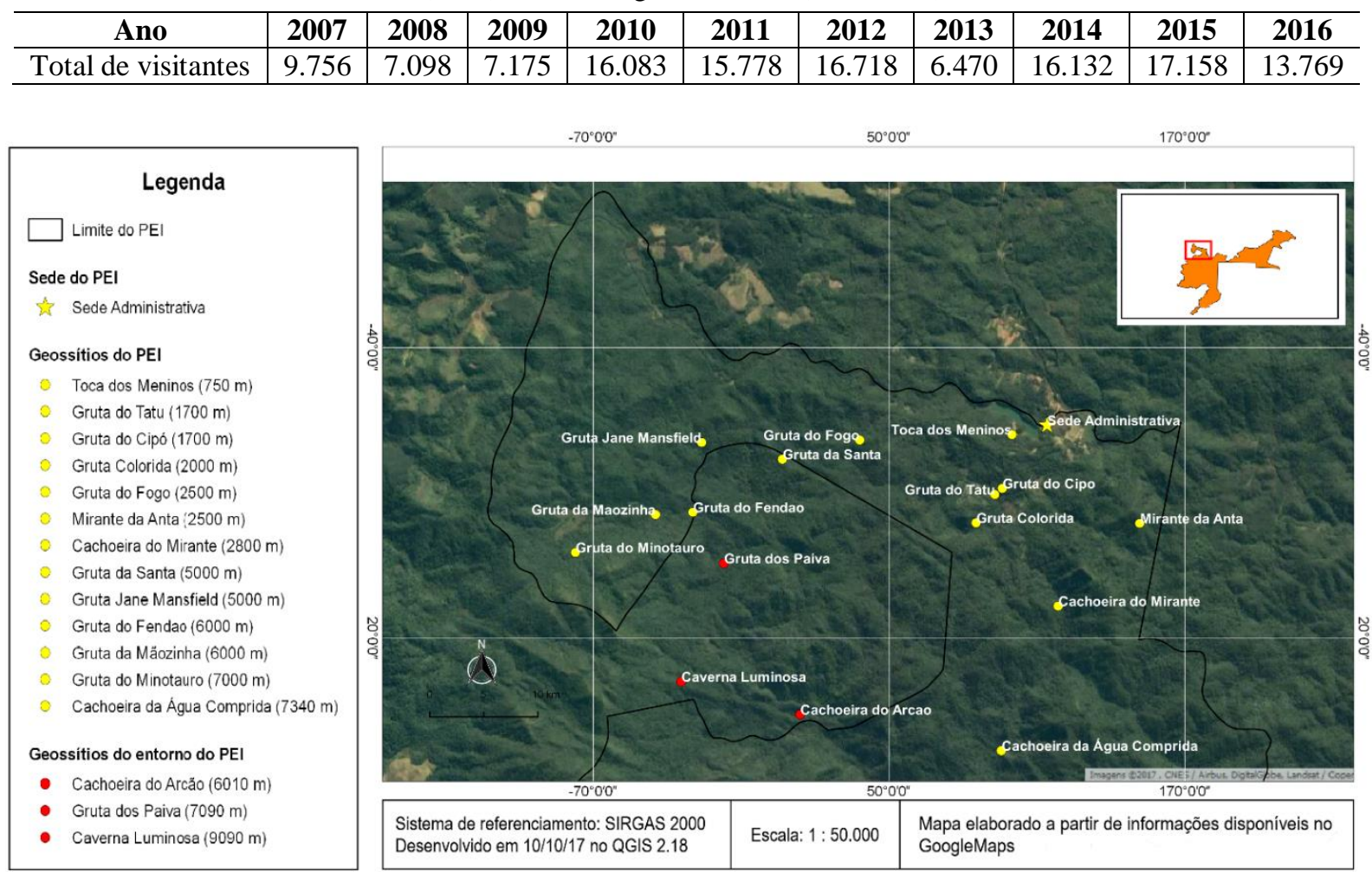

Figura 4 - Distância e localização da sede administrativa do PEI em relação aos sítios selecionados.

\section{Definição do Método de Análise dos Sítios Selecionados}

A valoração dos sítios do PEI foi realizada com base nos valores para a geodiversidade anteriormente propostos nas pesquisas de Pereira (2010) e Ferreira (2014): Intrínseco (Vi), Científico (Vci), Turístico (Vtur) e de Uso e Gestão (Vug). Além destes, foi proposto um novo valor, o Educacional (Ved). A proposição desta nova categoria de valor partiu de parâmetros já definidos nas pesquisas de Pereira (2010) e Ferreira (2014) para outras categorias, mas que foram observados sob nova abordagem. Além disso, foi também desenvolvido e aplicado um novo parâmetro (Figura 5).

Os parâmetros 20, 21 e 22 do Ved foram adaptados de parâmetros já existentes nos demais valores considerados na valoração dos sítios, mas que foram repensados sob a ótica de sua representatividade para a educação. Para o P20 do Ved, seguiu-se a lógica de associação do sítio com outros tipos de interesse (dentro das geociências) ou outras Grandes Áreas de estudo (ex.: Humanas, Exatas, Biológicas) que envolvem de modo geral as temáticas para os níveis de formação relacionando com as áreas de interesse. O P21 é relacionado à relevância didática e analisa o potencial do sítio para ilustrar elementos ou processos da geodiversidade e possibilidade de uso para o ensino nos diferentes níveis de formação. Para tanto, considera as áreas de conhecimento (Linguagens, Ciências da Natureza, Ciências Humanas), com fundamento na Base Nacional Comum Curricular (BRASIL, 2016) e nas Orientações Curriculares para o Ensino Médio (BRASIL, 2006) (Figura 6). Para as graduações e pós-graduações seguiu-se a mesma linha de comparação com cada área de conhecimento.

$\mathrm{O}$ desenvolvimento do P22 teve como enfoque a relevância do aspecto histórico, propondo a análise da ilustração e a associação dos pontos de parada das trilhas que levam aos sítios sendo pertinentes ao estudo do meio tanto da biodiversidade quanto geodiversidade, já que em alguns trechos das trilhas do PEI pode-se fazer paradas para a explicação de temas que envolvem os assuntos pertinentes a cada nível de formação.

O novo parâmetro P23 do Ved retratou o nível da educação e formação do indivíduo, buscando mostrar o potencial do sítio para ilustrar elementos ou processos da geodiversidade e possibilidade de 
uso do local para ensino nos diferentes níveis, bem como se a área pode ser usada em trabalhos de campo (estudo do meio) de componentes curriculares diversos. Com o P23, é possível destacar qual o tipo de uso mais direcionado: se para um público mais especializado (graduação e pós-graduação), devido a peculiaridades de cunho científico do local visitado; ou se engloba apenas para um nível de formação, dois níveis, três níveis, ou ainda, se pode ser utilizado para um público de qualquer nível.

\begin{tabular}{|c|c|}
\hline & Parâmetros \\
\hline $\begin{array}{l}\text { Valor Intrínseco } \\
\text { (Vi) }\end{array}$ & $\begin{array}{l}\text { 1. Vulnerabilidade associada a processos naturais } \\
\text { 2. Abundância / Raridade } \\
\text { 3. Integridade } \\
\text { 4. Variedade de elementos da geodiversidade }\end{array}$ \\
\hline $\mathbf{V i}$ & Indicador $A=>1$ a $4($ A1 A2 A3 A4) \\
\hline $\begin{array}{l}\text { Valor científico } \\
\text { (Vci) }\end{array}$ & $\begin{array}{c}\text { 5. Grau de conhecimento científico } \\
\text { 6. Representatividade de materiais e processos geológicos } \\
\text { 7. Diversidade de interesses / temáticas associados } \\
\text { 8. Relevância didática }\end{array}$ \\
\hline Vci & Indicador B => 5 a $8($ B1 B2 B3 B4) \\
\hline $\begin{array}{l}\text { Valor Turístico } \\
\text { (Vtur) }\end{array}$ & $\begin{array}{c}\text { 9. Aspecto estético } \\
\text { 10. Acessibilidade } \\
\text { 11. Presença de infraestrutura } \\
\text { 12. Existência de sinalização em curso } \\
\text { 13. Presença de mecanismos no controle de visitantes }\end{array}$ \\
\hline Vtur & Indicador C => 9 a 13 (C1 C2 C3 C4 C5) \\
\hline $\begin{array}{l}\text { Valor de Uso/ } \\
\text { Gestão (Vug) }\end{array}$ & $\begin{array}{c}\text { 14. Relevância cultural } \\
\text { 15. Relevância econômica } \\
\text { 16. Nível oficial de proteção } \\
\text { 17. Vulnerabilidade associada ao uso antrópico } \\
\text { 18. População do núcleo urbano mais próximo } \\
\text { 19. Condições socioeconômicas dos núcleos urbanos mais próximos }\end{array}$ \\
\hline Vug & Indicador D => 14 a 19 (D1 D2 D3 D4 D5 D6) \\
\hline $\begin{array}{c}\text { Valor Educacional } \\
\text { (Ved) }\end{array}$ & $\begin{array}{l}\text { 20. Diversidade de interesses / áreas de estudo / temáticas associados } \\
\text { 21. Aplicação didática } \\
\text { 22. Relevância do aspecto histórico } \\
\text { 23. Nível da educação e formação }\end{array}$ \\
\hline Ved & Indicador $E=>20$ a $23($ E1 E2 E3 E4) \\
\hline
\end{tabular}

Figura 5 - Parâmetros propostos para o Valor Educacional. Em itálico: valor e parâmetro novos, propostos na presente pesquisa. Fonte dos demais parâmetros: Pereira (2010) e Ferreira (2014).

\begin{tabular}{|c|c|c|c|}
\hline $\begin{array}{l}\text { EDUCAÇÃO / } \\
\text { FORMAÇÃO }\end{array}$ & ÁREAS DO CONHECIMENTO & $\begin{array}{l}\text { COMPONENTES } \\
\text { CURRICULARES }\end{array}$ & Fonte \\
\hline \multirow{5}{*}{$1^{\circ}$ ao $5^{\circ}$ ano $/ 6^{\circ}$ ao $9^{\circ}$ ano } & Linguagens & Educação Física & \multirow{5}{*}{$\begin{array}{l}\text { (BRASIL, } \\
\text { 2016) }\end{array}$} \\
\hline & \multirow{2}{*}{ Ciências da Natureza } & Ciências & \\
\hline & & Educação Ambiental * & \\
\hline & \multirow{2}{*}{ Ciências Humanas } & Geografia & \\
\hline & & História & \\
\hline \multirow{6}{*}{ Ensino Médio } & Linguagens, Códigos e suas Tecnologias & Educação Física & $\begin{array}{l}\text { (BRASIL, } \\
\text { 2006a) }\end{array}$ \\
\hline & \multirow{3}{*}{$\begin{array}{c}\text { Ciências da Natureza, Matemática e suas } \\
\text { Tecnologias }\end{array}$} & Biologia & \multirow{3}{*}{$\begin{array}{c}\text { (BRASIL } \\
\text { 2006b) }\end{array}$} \\
\hline & & Química & \\
\hline & & Educação Ambiental * & \\
\hline & \multirow{2}{*}{ Ciências Humanas e suas Tecnologias } & Geografia & \multirow{2}{*}{$\begin{array}{c}\text { (BRASIL, } \\
2006 \mathrm{c})\end{array}$} \\
\hline & & História & \\
\hline $\begin{array}{c}\text { Graduação/Pós- } \\
\text { Graduação }\end{array}$ & \multicolumn{2}{|c|}{ Diversas Graduações / Pós - Graduações } & - \\
\hline
\end{tabular}

Figura 6 - Níveis e componentes curriculares. * Educação Ambiental: Tema Transversal.

Os parâmetros são avaliados pela descrição de critérios de pontuação que seguem uma escala de 0 indicadores de qualidade os quais possuem a 4 e representa o Vi, Vci, Vtur, Vug e o Ved. Os 
indicadores utilizados para a análise do o Vi, Vci, Vtur e Vug são os mesmos utilizados por Ferreira (2014). Para os novos parâmetros do Ved, foram desenvolvidos indicadores específicos, conforme a realidade da área pesquisada (Figuras 7-10).

Entende-se que existe um grau de subjetividade na aplicação dos parâmetros, indicadores e critérios apontados, o que é inerente em pesquisas descritivas e valorativas (Pereira, 2010; Folloni, 2014). No entanto, considerando se tratar de uma linha de pesquisa em desenvolvimento e com procedimentos já fixados, optou-se por segui-la para permitir a inserção dos resultados da presente pesquisa dentro do universo do tema.

\begin{tabular}{|c|c|c|}
\hline Título & Código & Descrição \\
\hline Parâmetro & P20 & Diversidade de interesses / áreas de estudo / temáticas associadas \\
\hline \multirow{2}{*}{$\begin{array}{c}\text { Descrição do indicador } \\
\text { Critério de pontuação }\end{array}$} & E1 & $\begin{array}{c}\text { Associação do sítio com outros tipos de interesse (dentro das geociências) ou } \\
\text { outras áreas de estudo (ex.: Humanas, Exatas, Biológicas) }\end{array}$ \\
\hline \multirow{3}{*}{\begin{tabular}{c} 
para o P20 \\
\cline { 2 - 3 }
\end{tabular}} & 0 pt. & Sem associação com outras áreas de estudo \\
\cline { 2 - 3 } & $1 \mathrm{pt}$. & Apenas 1 Tipo de interesse ou área de estudo \\
\cline { 2 - 3 } & $3 \mathrm{pts}$. & Dois (2) tipos de interesses ou áreas de estudos \\
\cline { 2 - 3 } & $4 \mathrm{pts}$. & Três (3) tipos de interesses ou áreas de estudos \\
\hline
\end{tabular}

Figura 7 - Critérios de pontuação do parâmetro P20.

\begin{tabular}{|c|c|c|}
\hline Título & Código & Descrição \\
\hline Parâmetro & $\mathrm{P} 21$ & Aplicação Didática \\
\hline $\begin{array}{l}\text { Descrição do } \\
\text { indicador }\end{array}$ & E2 & $\begin{array}{l}\text { Potencial do sítio para ilustrar elementos ou processos da geodiversidade e } \\
\text { possibilidade de uso do local para ensino das geociências e / ou escolas secundárias. } \\
\text { Considera as OCEM, os BNCC e verifica os conteúdos de cada nível }\end{array}$ \\
\hline \multirow{5}{*}{$\begin{array}{l}\text { Critério de } \\
\text { pontuação para o } \\
\text { P21 }\end{array}$} & 0 pt. & Sem aplicação didática \\
\hline & 1 pt. & $\begin{array}{l}\text { Aplica conteúdos curriculares de diversas graduações / pós-graduações. Devido a } \\
\text { especificidade do local visitado, bem como a longa distância e dificuldade de acesso }\end{array}$ \\
\hline & 2 pts. & $\begin{array}{l}\text { Aplica conteúdos curriculares de diversas disciplinas do ensino médio, do ensino } \\
\text { fundamental do } 1^{\circ} \text { ao } 5^{\circ} \text { ano ou } 6^{\circ} \text { ao } 9^{\circ} \text { ano }\end{array}$ \\
\hline & 3 pts. & $\begin{array}{l}\text { Aplica conteúdos curriculares de diversas disciplinas do ensino médio, do ensino } \\
\text { fundamental do } 1^{\circ} \text { ao } 5^{\circ} \text { ano e } 6^{\circ} \text { ao } 9^{\circ} \text { ano }\end{array}$ \\
\hline & 4 pts. & $\begin{array}{l}\text { Muito ilustrativo e passível de ser utilizado p/ fins de aplicação didática por públicos } \\
\text { de qualquer nível, desde leigos até especialistas }\end{array}$ \\
\hline
\end{tabular}

Figura 8 - Critérios de pontuação do parâmetro P21.

\begin{tabular}{|c|c|c|}
\hline Título & Código & Descrição \\
\hline Parâmetro & $\mathrm{P} 22$ & Relevância do Aspecto Histórico \\
\hline $\begin{array}{l}\text { Descrição do } \\
\text { indicador }\end{array}$ & E3 & $\begin{array}{c}\text { Analisa a ilustração e a associação dos pontos de parada das principais trilhas } \\
\text { que levam aos geossítios com a realização de estudo do meio }\end{array}$ \\
\hline \multirow{5}{*}{$\begin{array}{c}\text { Critério de pontuação } \\
\text { para o P22 }\end{array}$} & 0 pt. & $\begin{array}{l}\text { Sem qualquer relação com ponto de parada para análise de elementos do } \\
\text { aspecto histórico }\end{array}$ \\
\hline & $1 \mathrm{pt}$. & $\begin{array}{c}\text { Pelo menos } 1 \text { ponto de parada não obrigatória para análise de elementos do } \\
\text { aspecto histórico }\end{array}$ \\
\hline & 2 pts. & $\begin{array}{c}\text { Até } 2 \text { pontos de paradas não obrigatórias para análise de elementos do aspecto } \\
\text { histórico }\end{array}$ \\
\hline & 3 pts. & $\begin{array}{l}\text { Presença de algum elemento do aspecto histórico, que tenha uma contribuição } \\
\text { acessória p/ visitação ou uso do local }\end{array}$ \\
\hline & 4 pts. & $\begin{array}{l}\text { Estreita relação com elementos históricos (ruína, arquitetura), onde o aspecto } \\
\text { histórico seja um dos principais atrativos do local }\end{array}$ \\
\hline
\end{tabular}

Figura 9 - Critérios de pontuação do parâmetro P22.

\begin{tabular}{|c|c|c|}
\hline Título & Código & Descrição \\
\hline Parâmetro & P23 & Nível da Educação e Formação \\
\hline $\begin{array}{c}\text { Descrição do } \\
\text { indicador }\end{array}$ & E4 & $\begin{array}{c}\text { Potencial do sítio para ilustrar elementos ou processos da geodiversidade e } \\
\text { possibilidade de uso do local para ensino das geociências e/ou escolas secundárias. A } \\
\text { área é usada em trabalhos de campo (estudo do meio) de disciplinas diversas }\end{array}$ \\
\hline \multirow{2}{*}{$\begin{array}{c}\text { Critério de } \\
\text { pontuação para o } \\
\text { P23 }\end{array}$} & 0 pt. & $\begin{array}{c}\text { Uso mais direcionado para público especializado (graduação e pós-graduação), } \\
\text { devido a especificidade do local visitado }\end{array}$ \\
\cline { 2 - 3 } & 1 pt. & Apenas para 1 Nível \\
\cline { 2 - 3 } & 2 pts. & Apenas para 2 Níveis \\
\cline { 2 - 3 } & 4 pts. & Apenas para 3 Níveis \\
\hline
\end{tabular}

Figura 10 - Critérios de pontuação do parâmetro P23. 


\section{Procedimentos de Coleta e Análise De Dados}

Para a coleta de dados, foi utilizada uma ficha de campo baseada em Ferreira (2014). Antes da pesquisa de campo, a ficha foi preenchida com a obtenção de dados secundários retirados dos planos de manejo (Fundação Florestal, 2008, 2010).

A análise dos dados coletados de cada sítio foi feita com base na média da pontuação dos valores qualificados e quantificados dos dados coletados. Para tanto, foram calculadas as médias aritméticas para cada valor analisado, conforme o total de parâmetros analisados por valor. A média obtida após o cálculo de valoração gerou uma pontuação de cada categoria de valoração (Vi, Vci, Vtur, Vug, Ved), a qual foi multiplicada por pesos préestabelecidos nas metodologias de valoração de sítios. Este procedimento foi utilizado para a obtenção de cada um dos Valores analisados para o conjunto de locais inventariados (Equações 1 à 3).

$$
\begin{array}{ll}
\text { VUC }=\left(2^{*} \mathrm{Vi}+3^{*} \mathrm{Vci}\right) / 5 & \text { [Equação 1] } \\
\text { VUT }=\left(3^{*} \mathrm{Vtur}+2^{*} \mathrm{Vug}\right) / 5 & \text { [Equação 2] } \\
\text { VUTE }=\left(3^{*} \mathrm{Ved}+2 * \mathrm{Vtur}+\mathrm{Vug}\right) / 6 & \text { [Equação 3] } \\
\text { Onde: } &
\end{array}
$$

VUC $=$ Valor de Uso Científico; VUT $=$ Valor de Uso Turístico; e VUTE = Valor de Uso Turístico-Educacional.

O Ranking de Relevância dos sítios inventariados foi calculado de duas formas: utilizando a equação original [Equação 4] de Ferreira (2014) e a nova equação proposta [Equação 5], a qual substitui o VUT pelo VUTE.

$\mathrm{R}=\{2 *[(\mathrm{VUC} / 23) * 100]+[(\mathrm{VUT} / 23) * 100]\} / 3[$ Equação 4]

Onde: $\mathrm{R}=$ Ranking de Relevância; VUC =
Valor de Uso Científico; e VUT = Valor de Uso Turístico.

\section{$\mathrm{R}=\{2 *[(\mathrm{VUC} / 23) * 100]+[(\mathrm{VUTE} / 23) * 100]\} / 3[$ Equação 5]}

Onde: $\mathrm{R}=$ Ranking de Relevância; VUC = Valor de Uso Científico; e VUTE = Valor de Uso Turístico-Educacional.

Com isso, foi calculada a relevância de cada sítio inventariado do PEI por duas formas: a tradicional e a alternativa proposta nesta pesquisa, com o uso do Valor de Uso Turístico-Educacional (VUTE) no lugar do Valor de Uso Turístico (VUT). Depois da seleção dos sítios inventariados do PEI, a relevância dos mesmos foi obtida a partir dos índices de VUC, VUT e VUTE. Esses valores foram divididos por 23, que representa o número total de parâmetros aplicados na avaliação dos sítios. Para finalizar, foi calculada uma média ponderada, com peso maior ao VUC, considerando que a condição científica se faz presente no potencial turístico tanto quanto no turísticoeducacional.

Destaca-se que não foi utilizada a equação Valor de Conservação indicada na metodologia de Ferreira (2014). Esta opção foi tomada considerando que os sítios avaliados estão dentro ou no entorno de uma UC de Proteção Integral, de forma que entende-se que sua conservação, por ora, já está resguarda pelos diplomas legais de criação e os Planos de Manejo do PEI. Assim, reafirma-se que o intuito principal foi de estabelecer e verificar o potencial de utilização dos sítios analisados como atrativo turístico, além do seu uso educacional através da adaptação proposta para o Valor de Uso Turístico-Educacional.

\section{RESULTADOS E DISCUSSÃO}

Os resultados foram tabulados através da síntese da quantificação dos sítios analisados. A ficha de e caracterização proporcionou a pontuação para os sítios escolhidos neste trabalho. Estes foram relacionados com os parâmetros e os indicadores do Figura 5. Assim, foram categorizados a partir de seus valores: intrínseco, científico, turístico, uso/gestão e o educacional (Figura 11).

De acordo com a avaliação e apontamento dos resultados do Vi, Vci, Vtur, Vug e Ved no presente trabalho os 16 sítios foram categorizados como geossítios, o que se evidencia pela pontuação significativa para as categorias de valores avaliadas (Brilha, 2005; Araújo, 2005; Garcia et al., 2017).
A categoria Vci tem como referência os trabalhos de pesquisa que evolvem o local e suas potencialidades para ilustrar aspectos relevantes da geologia da área.

No Vci do PEI, o destaque maior é para os geossítios gruta Colorida, Jane Mansfield, Luminosa, Mãozinha, toca dos Meninos, gruta dos Paiva, mirante da Anta e cachoeira do Arcão. $\mathrm{Na}$ análise feita, verifica-se que a Representatividade de Materiais e Processos Geológicos e a Diversidades de Interesses / Temáticas Associadas (P6, P7, Figura 11) são os parâmetros que fazem sobressair os geossítios Mãozinha, Paiva e Arcão em relação à média geral. Já os geossítios toca dos Meninos, cachoeira do Arcão e o mirante da Anta têm 
como representatividade maior os Processos Geológicos e a Diversidades de Interesses / Temáticas Associadas e na Relevância Didática (P7, P8, Figura 11).

O Vug reúne os parâmetros ligados à relevância cultural (lendas, religião), condições socioeconômicas das áreas de entorno, nível oficial de proteção, possibilidade de utilização dos geossítios e vulnerabilidade perante o uso. Tudo isso expressa o indicativo dos impactos sociais e viabilidade de utilização do geossítio, bem como da disponibilidade de aplicação de investimentos para valorização do local (Pereira, 2010; Ferreira, 2014)

\begin{tabular}{|c|c|c|c|c|c|c|c|c|c|c|c|c|c|c|c|c|c|}
\hline \multirow[b]{2}{*}{$\frac{\mathscr{Z}}{\stackrel{\Xi}{\sigma}}$} & \multirow[b]{2}{*}{ 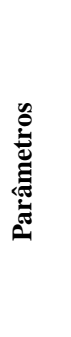 } & \multicolumn{16}{|c|}{ Geossítios analisados } \\
\hline & & 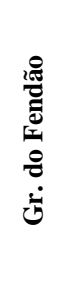 & 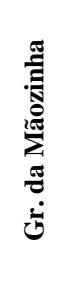 & 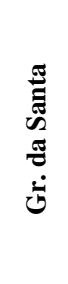 & 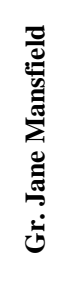 & 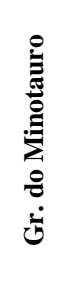 & 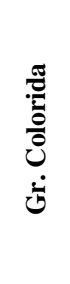 & 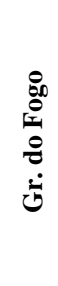 & 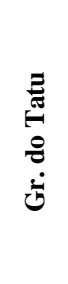 & 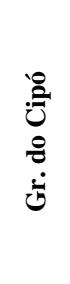 & 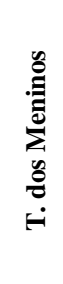 & 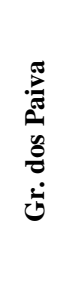 & 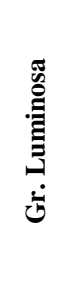 & 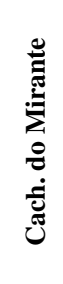 & 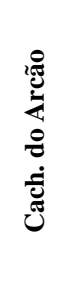 & 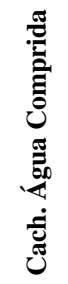 & 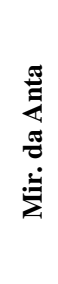 \\
\hline \multirow{4}{*}{$\mathbf{V i}$} & $\mathrm{P} 1$ & 2 & 0 & 2 & 2 & 2 & 2 & 2 & 2 & 2 & 2 & 4 & 4 & 4 & 4 & 4 & 2 \\
\hline & $\mathrm{P} 2$ & 4 & 2 & 2 & 4 & 4 & 2 & 2 & 2 & 2 & 2 & 4 & 4 & 2 & 3 & 3 & 2 \\
\hline & P3 & 4 & 3 & 3 & 3 & 1 & 3 & 3 & 3 & 3 & 3 & 3 & 4 & 4 & 4 & 4 & 3 \\
\hline & $\mathrm{P} 4$ & 4 & 4 & 3 & 4 & 4 & 3 & 3 & 2 & 1 & 2 & 4 & 3 & 2 & 2 & 2 & 3 \\
\hline \multicolumn{2}{|c|}{ Média Vi } & 3,50 & 2,25 & 2,50 & 3,25 & 2,75 & $\mathbf{3 , 0 0}$ & 2,50 & 2,25 & 2,00 & 2,25 & 3,75 & 3,75 & 3,00 & 3,25 & 3,25 & 2,50 \\
\hline \multirow{4}{*}{ Vci } & P5 & 1 & 1 & 2 & 1 & 1 & 2 & 1 & 1 & 1 & 1 & 2 & 1 & 0 & 0 & 0 & 0 \\
\hline & P6 & 4 & 4 & 2 & 4 & 2 & 2 & 2 & 2 & 2 & 2 & 4 & 2 & 2 & 4 & 2 & 2 \\
\hline & P7 & 0 & 4 & 1 & 1 & 0 & 2 & 0 & 0 & 0 & 4 & 4 & 4 & 3 & 4 & 3 & 4 \\
\hline & P8 & 3 & 1 & 4 & 3 & 1 & 4 & 3 & 2 & 2 & 4 & 4 & 3 & 3 & 4 & 4 & 4 \\
\hline \multicolumn{2}{|c|}{ Média Vci } & 2,25 & 2,75 & 2,25 & 2,50 & 1,25 & 2,50 & 1,75 & 1,50 & $\mathbf{1 , 5 0}$ & 3,00 & $\mathbf{3 , 5 0}$ & 2,50 & 2,00 & 3,00 & 2,25 & 2,50 \\
\hline \multirow{5}{*}{ Vtur } & P9 & 4 & 2 & 2 & 2 & 0 & 2 & 2 & 0 & 0 & 2 & 4 & 2 & 4 & 4 & 4 & 2 \\
\hline & P10 & 2 & 2 & 2 & 2 & 2 & 2 & 2 & 1 & 1 & 2 & 1 & 1 & 2 & 2 & 2 & 1 \\
\hline & P11 & 4 & 4 & 1 & 1 & 1 & 4 & 4 & 4 & 1 & 4 & 4 & 4 & 4 & 4 & 4 & 4 \\
\hline & P12 & 0 & 0 & 0 & 0 & 0 & 3 & 3 & 3 & 0 & 0 & 0 & 0 & 0 & 0 & 1 & 3 \\
\hline & P13 & 4 & 4 & 4 & 4 & 4 & 4 & 4 & 4 & 4 & 4 & 1 & 1 & 4 & 1 & 1 & 2 \\
\hline \multicolumn{2}{|c|}{ Méd. Vtur } & 2,8 & 2,4 & 1,8 & 1,8 & 1,4 & 3,0 & $\mathbf{3 , 0}$ & 2,4 & 1,2 & 2,4 & 2,0 & 1,6 & 2,8 & 2,2 & 2,4 & 2,4 \\
\hline \multirow{6}{*}{ Vug } & P14 & 1 & 1 & 3 & 1 & 1 & 1 & 1 & 1 & 1 & 1 & 1 & 1 & 1 & 1 & 1 & 1 \\
\hline & P15 & 4 & 4 & 4 & 4 & 4 & 4 & 4 & 4 & 4 & 4 & 4 & 4 & 4 & 4 & 4 & 4 \\
\hline & P16 & 4 & 4 & 4 & 4 & 4 & 4 & 4 & 4 & 4 & 4 & 3 & 3 & 4 & 3 & 3 & 4 \\
\hline & P17 & 2 & 0 & 2 & 4 & 2 & 2 & 2 & 2 & 2 & 2 & 2 & 2 & 2 & 4 & 4 & 2 \\
\hline & P18 & 1 & 1 & 1 & 1 & 1 & 1 & 1 & 1 & 1 & 1 & 1 & 1 & 1 & 1 & 1 & 1 \\
\hline & P19 & 1 & 1 & 1 & 1 & 1 & 1 & 1 & 1 & 1 & 1 & 1 & 1 & 1 & 1 & 1 & 1 \\
\hline \multicolumn{2}{|c|}{ Média Vug } & 2,15 & $\mathbf{1 , 8 3}$ & 2,50 & 2,50 & 2,17 & 2,17 & 2,17 & 2,17 & 2,17 & 2,17 & 2,00 & 2,00 & 2,17 & 2,33 & 2,33 & 2,17 \\
\hline \multirow{4}{*}{ Ved } & P20 & 2 & 2 & 3 & 3 & 1 & 4 & 3 & 2 & 2 & 2 & 4 & 3 & 3 & 3 & 3 & 3 \\
\hline & P21 & 1 & 4 & 4 & 4 & 1 & 4 & 4 & 1 & 1 & 4 & 4 & 1 & 2 & 4 & 4 & 4 \\
\hline & P22 & 0 & 0 & 0 & 0 & 0 & 0 & 0 & 0 & 0 & 0 & 1 & 0 & 1 & 0 & 0 & 1 \\
\hline & P23 & 2 & 0 & 2 & 2 & 4 & 4 & 4 & 0 & 0 & 4 & 4 & 0 & 4 & 4 & 4 & 4 \\
\hline \multicolumn{2}{|c|}{ Média Ved } & 1,25 & 1,50 & 2,25 & 2,25 & $\mathbf{1 , 5 0}$ & $3, \mathbf{0 0}$ & 2,75 & 0,75 & 0,75 & 2,50 & 3,25 & 1,00 & 2,50 & 2,75 & 2,75 & 3,00 \\
\hline
\end{tabular}

Figura 11 - Síntese da quantificação dos geossítios inventariados no PEI. 
Em relação ao Vug do PEI (Figura 11), as cachoeiras do Arcão (entorno) e da Água Comprida obtiveram 0.14 décimos acima da média geral e tiveram também as mesmas pontuações em todos os parâmetros do Vug (Figura 11). O apontamento feito para atingir essa avaliação se dá pela distância entre a sede administrativa e estes geossítios, atingindo entre $6 \mathrm{~km}$ e $7 \mathrm{~km}$. Com isto, a visitação não atinge uma grande quantidade dependendo do perfil do visitante, que nem sempre está disposto a percorrer maiores distâncias. Sobre a pontuação da gruta da Santa e Jane Mansfield, ambas com 2,50, ultrapassam 0.31 décimos da média geral $(2,19)$. Tal disparidade se faz presente na Relevância Cultural (P14, Figura 11), pois a gruta da Santa é categorizada como um geossítio com presença de elemento cultural, o qual tem uma contribuição acessória para a visitação ou uso do local. Sendo assim, recebeu a nota 3, enquanto a Jane Mansfield recebeu nota 1 . Sobre a Vulnerabilidade Associada ao Uso Antrópico (P17, Figura 11), a gruta da Santa recebe nota 2 e a Jane Mansfield nota 4, concluindo o Vug.

A vocação turística do PEI fica evidente pela observação dos resultados para o Vtur na figura 11. Do total de geossítios analisados, $56 \%$ tiveram Vtur acima da média. Os resultados obtidos são condizentes com os dados de visitação do Parque, pois tratam-se de roteiros consolidados e muito procurados pelos visitantes. Destaques são dados para as grutas Colorida e do Fogo, que possuem a mesma pontuação nos cinco parâmetros, denotando as maiores médias acima da geral com a relevância para a Presença de Infraestrutura e Visitação e Atividades Realizadas (P11, P13, Figura 11), devido à proximidade da sede. A Gruta do Fendão e a Cachoeira do Mirante também estão acima da média: o primeiro geossítio se destaca por atrair visitantes que se interessam por um roteiro turístico de aventura, mais esportivo e restritivo; o segundo, apesar de seguir um controle do número de visitantes sem um estudo aprimorado, é local de realização de atividades de ecoturismo e turismo educacional, com escolas do ensino fundamental, ensino médio e superior.

Os geossítios gruta da Mãozinha, Tatu, toca dos Meninos, mirante da Anta e cachoeira da Água Comprida superaram a média, mas contrastam suas pontuações de 0 a 4 para o Aspecto Estético e de 0 e 3 na maioria dos geossítios para Sinalização e Informação (P9, P12, Figura 11). Este último parâmetro comentado é um dos que precisam de mais atenção da gestão do PEI, com a aplicação de uma padronização de sinalização para todos os geossítios pesquisados.

Os públicos escolares de todos os níveis estão entre os principais usuários dos roteiros turísticos do PEI. Assim, é quase impossível dissociar turismo de educação neste contexto. Além disso, Neiman (2007) defende o desenvolvimento de atividades especiais no âmbito da educação, que intensifiquem o contato do ser humano com a natureza.

Estas podem contribuir para o afloramento de motivações que levem à mudança dos hábitos culturais, o que pode formar cidadãos mais conscientes e atuantes na conservação ambiental. As Orientações Curriculares para o Ensino Médio (OCEM) recomendam o desenvolvimento de práticas externas ao espaço escolar como motivadoras para os alunos, justamente por deslocarem o ambiente de aprendizagem para o local de ocorrência dos fenômenos (BRASIL, 2006). Neste sentido, de um modo geral sobre todos os níveis de educação, as atividades externas à sala de aula dão relevo ao aprendizado a respeito da natureza e dinâmica do meio ambiente, de maneira que a atividade de campo possa proporcionar um interessante elo entre a teoria e o ambiente.

Para a nova proposta de categoria de valor, o Ved, dos 16 geossítios estudados, 10 estão acima da média geral. A representatividade da gruta dos Paiva é a maior de todas e atinge uma avalição igual a 3.25, isso corresponde 1.14 acima da média mesmo sendo um geossítio que está no entorno do PEI e localizado a uma distância de aprox. $7 \mathrm{~km}$ da sede administrativa. A gruta recebeu pontuação 4 nos parâmetros Diversidade de Interesses / Áreas de Estudo / Temáticas Associadas, Aplicação Didática e Nível da Educação e Formação (P20, P21, P23, Figura 11), pois possui mais de três tipos de interesse ou área de estudo, é passível de ser utilizada para fins de aplicação didática para leigos até especialistas, e pode ser utilizada para público de qualquer nível de formação.

Ainda acima da média, a gruta Colorida e o mirante da Anta alcançaram 3.00 pontos, se igualando entre sina pontuação do parâmetro Nível de Educação e Formação (P23, Figura 11) e se diferenciando nos outros parâmetros. O 
destaque que ocasiona uma significância para esses geossítios é o parâmetro de Relevância do Aspecto Histórico (P22, Figura 11).

Dando continuidade à análise dos dados e seguindo os procedimentos estabelecidos em Pereira (2010) e Ferreira (2014), foram calculados os Valores de Uso Científico (VUC), de Uso Turístico (VUT) e o Ranking de
Relevância, conforme os métodos citados (RT). Além disso, para efeito de comparação, foram também calculados o Valor de Uso TurísticoEducacional (VUTE) e o Ranking de Relevância que considera o VUTE em sua equação, ora denominado de Ranking Proposto (RP). Os resultados dos cálculos são apresentados na figura 12 .

\begin{tabular}{|c|c|c|c|c|c|c|c|c|c|c|}
\hline Geossítios & Vi & Vci & Vtur & Vug & Ved & VUC & VUT & VUTE & RT & RP \\
\hline Gruta do Fendão & 3,50 & 2,25 & 2,80 & 2,17 & 1,25 & 2,75 & 2,55 & 1,92 & 11,66 & 10,75 \\
\hline Gruta da Mãozinha & 2,25 & 2,75 & 2,40 & 1,83 & 1,50 & 2,55 & 2,17 & 1,86 & 10,54 & 10,08 \\
\hline Gruta da Santa & 2,50 & 2,25 & 1,80 & 2,50 & 2,25 & 2,35 & 2,08 & 2,14 & 9,83 & 9,92 \\
\hline Gruta Jane Mansfield & 3,25 & 2,50 & 1,80 & 2,50 & 2,25 & 2,80 & 2,08 & 2,14 & 11,13 & 11,22 \\
\hline Gruta do Minotauro & 2,75 & 1,25 & 1,40 & 2,17 & 1,50 & 1,85 & 1,71 & 1,58 & 7,84 & 7,65 \\
\hline Gruta Colorida & 3,00 & 2,50 & 3,00 & 2,17 & 3,00 & 2,70 & 2,67 & 2,86 & 11,69 & 11,97 \\
\hline Gruta do Fogo & 2,50 & 1,75 & 3,00 & 2,17 & 2,75 & 2,05 & 2,67 & 2,74 & 9,81 & 9,91 \\
\hline Gruta do Tatu & 2,25 & 1,50 & 2,40 & 2,17 & 0,75 & 1,80 & 2,31 & 1,54 & 8,56 & 7,44 \\
\hline Gruta do Cipó & 2,00 & 1,50 & 1,20 & 2,17 & 0,75 & 1,70 & 1,59 & 1,14 & 7,23 & 6,57 \\
\hline Toca dos Meninos & 2,25 & 3,00 & 2,40 & 2,17 & 2,50 & 2,70 & 2,31 & 2,41 & 11,17 & 11,32 \\
\hline Gruta dos Paiva (entorno) & 3,75 & 3,50 & 2,00 & 2,00 & 3,25 & 3,60 & 2,00 & 2,63 & 13,33 & 14,24 \\
\hline Gruta Luminosa (entorno) & 3,75 & 2,50 & 1,60 & 2,00 & 1,00 & 3,00 & 1,76 & 1,37 & 11,25 & 10,68 \\
\hline Cachoeira do Mirante & 3,00 & 2,00 & 2,80 & 2,17 & 2,50 & 2,40 & 2,55 & 2,54 & 10,65 & 10,64 \\
\hline Cach. do Arcão (entorno) & 3,25 & 3,00 & 2,20 & 2,33 & 2,75 & 3,10 & 2,25 & 2,50 & 12,25 & 12,60 \\
\hline Cach. da Água Comprida & 3,25 & 2,25 & 2,40 & 2,33 & 2,75 & 2,65 & 2,37 & 2,56 & 11,12 & 11,40 \\
\hline Mirante da Anta & 2,50 & 2,50 & 2,40 & 2,17 & 3,00 & 2,50 & 2,31 & 2,66 & 10,59 & 11,10 \\
\hline Média & $\mathbf{2 , 8 6}$ & $\mathbf{2 , 3 1}$ & $\mathbf{2 , 2 3}$ & $\mathbf{2 , 1 9}$ & $\mathbf{2 , 1 1}$ & $\mathbf{2 , 5 3}$ & $\mathbf{2 , 2 1}$ & $\mathbf{2 , 1 6}$ & $\mathbf{1 0 , 5 4}$ & $\mathbf{1 0 , 4 7}$ \\
\hline
\end{tabular}

Figura 12 - Síntese dos resultados para os valores e rankings dos geossítios inventariados.

Os resultados obtidos são coerentes e consistentes com a realidade observada em campo no PEI, sobretudo para os usos científico e turístico-educacional. $\mathrm{O}$ Valor de Uso Científico (VUC - Figura 13), foi calculado a partir da média ponderada do Vi e Vci, sendo que os geossítios com pontuação acima da média foram 7 cavernas e 2 cachoeiras. Estas cavernas foram alvos de estudos de artigos científicos (e.g. Lenhare \& Sallun, 2015; Nunes et al., 2015) e referidos em nos planos de manejo (do Parque e Espeleológico).

As cachoeiras não apresentam a mesma abundância de estudos científicos que as abordem, mas juntamente com as cavernas, possuem elevada relevância didática. Os geossítios que apresentam o VUC abaixo da média e estão entre 2.35 e 2.50 refletem uma relevância didática que associa o geossítio com outras temáticas de estudo para públicos de qualquer nível, desde leigos a especialistas. Já as cavernas que estão entre 1.70 e 2.05 não representam uma relevância didática para todos os níveis, mas se destacam quanto ao grau de conhecimento científico, de maneira que são referidos em plano de manejo.

$\mathrm{Na}$ continuidade da descrição e análise dos dados, são apresentados os resultados para o tradicional Valor de Uso Turístico (VUT Ferreira, 2014) e o proposto Valor de Uso Turístico-Educacional (VUTE). As pontuações obtidas para os geossítios analisados para estas duas classes de valores são apresentadas na Figura 5, em conjunto com os dados de visitação anual de 2016 dos geossítios e sua respectiva distância em relação à sede do PEI, ponto de partida dos roteiros.

Primeiramente, destacam-se as pontuações para o VUT e VUTE dos geossítios avaliados (Figura 14). Para ambos os valores, 8 geossítios ficaram acima da média, variando apenas quais os geossítios foram mais bem pontuados. Os geossítios das grutas Colorida, do Fogo, dos Meninos, o mirante da Anta e as cachoeiras Água Comprida, Mirante e Arcão ficaram acima da média tanto para o VUT quanto para o VUTE. Os geossítios gruta do Fendão e gruta do Tatu ficaram acima da média apenas para o VUT, enquanto a gruta do Paiva foi pontuada acima da média apenas no VUTE. Além disso, as próprias 
médias não apresentaram variações significativas: 2,21 (VUT) e 2,16 (VUTE).

Em se tratando de valores de uso, foi também feita a comparação dos resultados obtidos com o uso turístico atual dos geossítios. O primeiro aspecto ressaltado é que a gruta do Minotauro não possui visitação atual, por determinação de seu Plano de Manejo Espeleológico (2010). Assim, para efeito de cálculo dos coeficientes de correlação entre os totais anuais de visitantes do ano de 2016 fornecidos pelo PEI em relação aos resultados obtidos para o VUT e VUTE, este geossítio foi suprimido, eliminando a distorção que geraria no resultado.

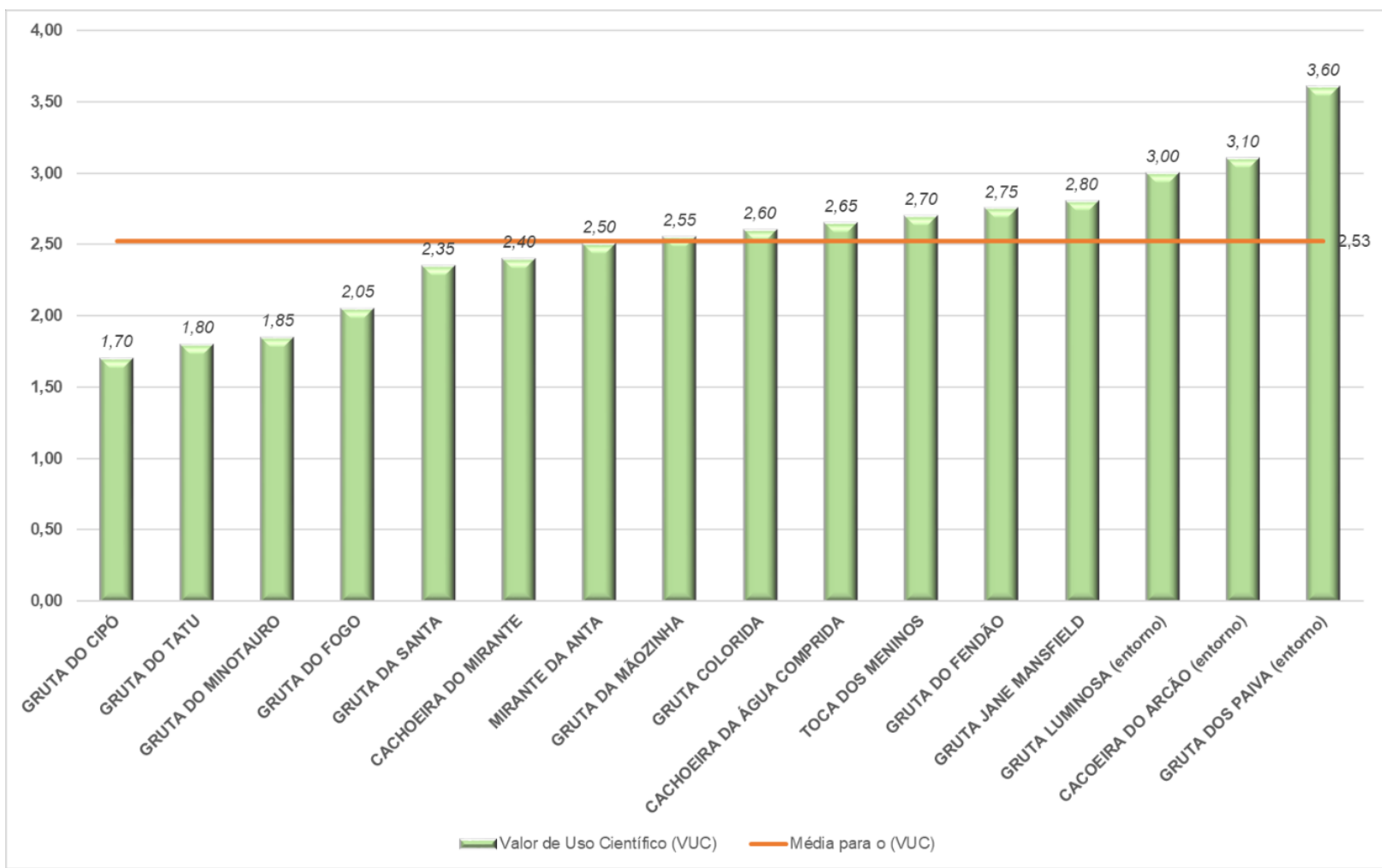

Figura 13 - Pontuação para o Valor de Uso Científico dos geossítios em relação à média geral.

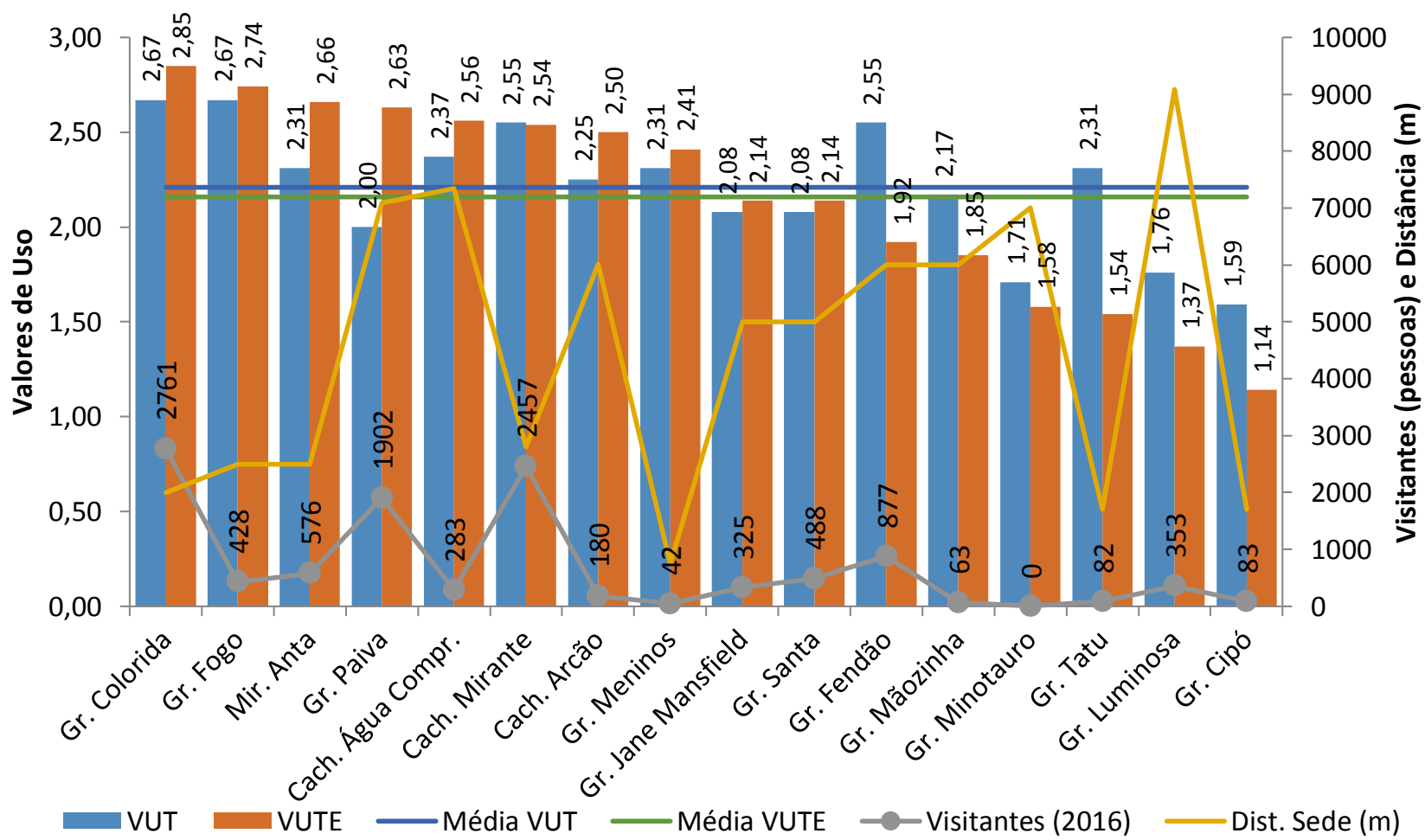

Figura 14 - Pontuação para os Valores de Uso Turístico (VUT) e Turístico-Educacional (VUTE) dos geossítios do PEI em relação ao total de visitantes por roteiro e à distância entre o geossítio e a sede do Parque. Fontes de dados: pesquisa dos autores; Gestão do PEI; Fundação Florestal (2008). 
Comparando os dados de visitação de 2016 com os valores do coeficiente $r$ de Pearson obtidos para o VUT e VUTE, observou-se uma correlação moderada entre o total de visitantes e o VUT $(0,41)$ e um pouco maior em relação ao $\operatorname{VUTE}(0,50)$, o que pode indicar que este, talvez, exprima sensivelmente melhor a realidade atual do PEI. A visitação também foi correlacionada com a distância entre os geossítios e a sede (0,08), evidenciando uma possível correlação inversamente proporcional entre distância e visitação, mas sem linearidade entre as séries de dados. Esta análise é balizadora dos resultados, pois evidencia que outros aspectos subjetivos norteiam a visitação atual dos geossítios, tais como a tradição de visitação de alguns geossítios, preferências de condutores locais e professores que levam os alunos, eventos (no caso da gruta da Santa) e o perfil do roteiro de visitação no geossítio (contemplação, estudo, aventura etc.).
Com isso, compreende-se que nem sempre um maior Valor de uso (Turístico ou TurísticoEducacional) resultará, necessariamente, em uma maior prática de uso de um geossítio. Esta mesma lógica se observa nos apontamentos de Fennel (2002), Beard et al. (2003) e Lobo et al. (2013) em outros casos de uso de recursos naturais para o turismo, respectivamente em atividades de ecoturismo, turismo de aventura e espeleoturismo.

Por fim, foi calculada a relevância geral dos geossítios estudados. Considerando que foram feitos cálculos de valores de uso por dois caminhos distintos (VUT e VUTE), também foram calculadas as relevâncias com o uso do caminho tradicional (RT) apontado pela literatura utilizada (Pereira, 2010; Ferreira, 2014) e a nova opção, denominada de relevância proposta (RP), com o uso do Valor de Uso Turístico-Educacional (Figura 15).

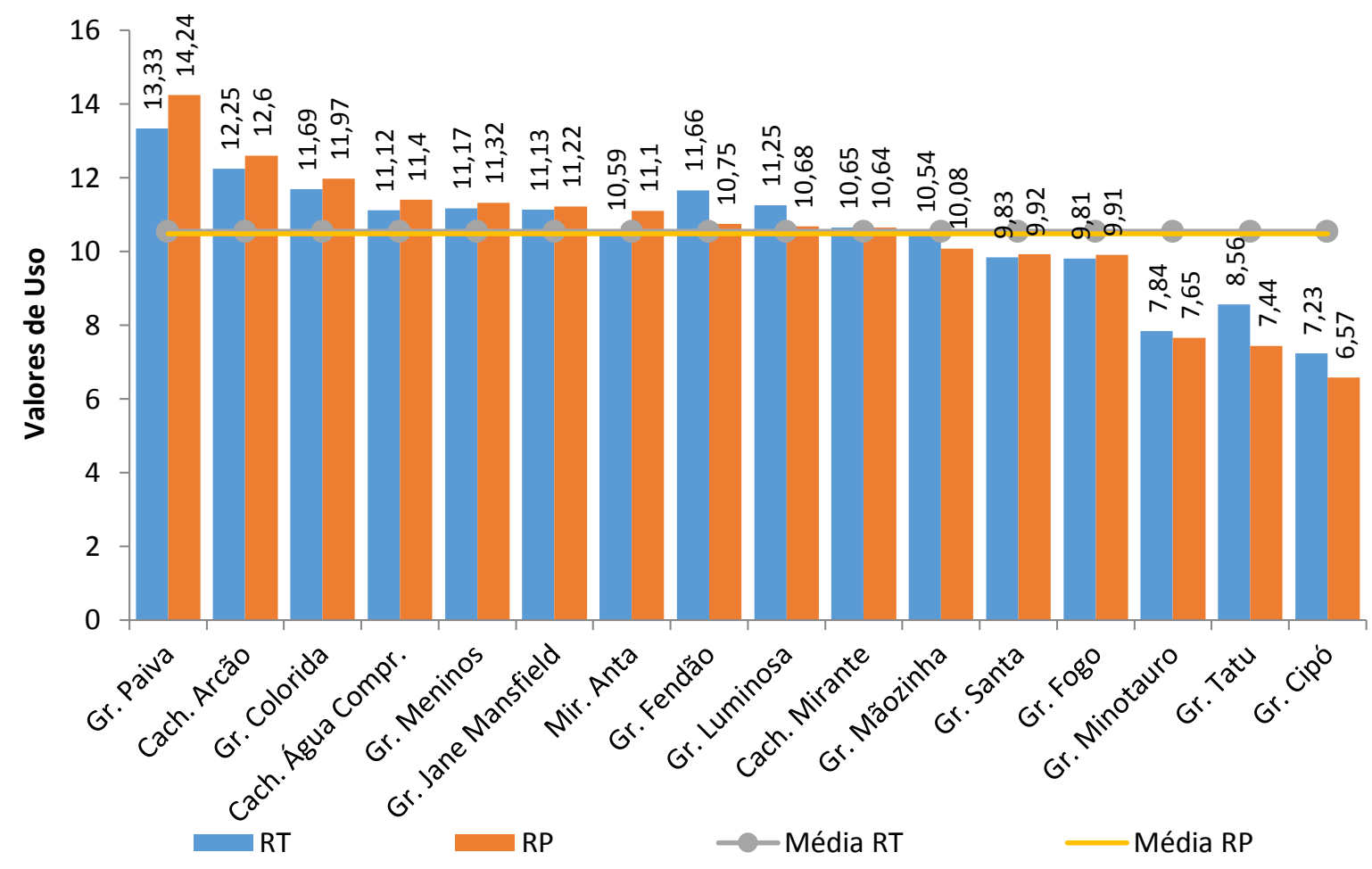

Figura 15 - Pontuações dos geossítios nos ranking de Relevância Tradicional (RT) e Proposto (RP).

O primeiro aspecto destacado da figura 15 é a baixa variação nas médias de RT $(10,54)$ e RP $(10,47)$. Tanto o RT quanto o RP apresentaram 10 geossítios acima da média, com o RT acrescentando a gruta Mãozinha em resultado igual à média. No entanto, o que chama mais atenção nos resultados da figura 14 , é o fato de que os dois geossítios com maiores pontuações em ambos os rankings de relevância (gruta dos Paiva e cachoeira do Arcão) estão localizados no entorno do PEI. A área onde tais geossítios se localizam é parte da Zona de Amortecimento do PEI, o que pela legislação brasileira (BRASIL, 2000) e pelo Plano de Manejo do PEI (Sistema Ambiental Paulista, 2009), restringe o seu uso direto, resguardando um nível mínimo de proteção a tais ambientes. Além disso, é preciso considerar que a cachoeira do Arcão, por ser parte de um curso d'água, é componente de Área de Preservação Permanente (APP), uma categoria de área natural protegida que também propicia a conservação de determinados 
elementos da geodiversidade.

Por sua vez, a gruta dos Paiva tem sua proteção inicialmente resguardada por ser Patrimônio e Bem da União (BRASIL, 1988) e componente elementar do Patrimônio Espeleológico (CONAMA, 2004).

Por fim, a relevância dos geossítios foi analisada em relação à importância em âmbito local, regional, nacional e internacional. Os resultados são apresentados na figura 16.
Dos geossítios do PEI, nenhum foi classificado com relevância internacional tanto para RT quanto para RP. Por outro lado, em ambos os rankings foi abundante a classificação dos geossítios em âmbito nacional, variando entre 10 e 11, conforme o ranking utilizado. Tal resultado é passível de comparação (Figura 17) com os resultados obtidos para outras áreas cársticas brasileiras, a Chapada Diamantina (Pereira, 2010) e o PETAR (Ferreira, 2014).

\begin{tabular}{|c|c|c|c|}
\hline & $\begin{array}{l}\text { Geossítios de relevância local } \\
\qquad(\mathrm{R}=<\mathbf{1 0})\end{array}$ & $\begin{array}{l}\text { Geossítios de relevância regional } \\
\qquad(\mathbf{1 0}<\mathbf{R}<\text { média })\end{array}$ & $\begin{array}{l}\text { Geossítios de relevância nacional } \\
\text { ( } R>\text { média) }\end{array}$ \\
\hline RT & $\begin{array}{c}\text { - Gruta do Cipó }(7,23) \\
\text { - Gruta do Minotauro }(7,84) \\
\text { - Gruta do Tatu }(8,56) \\
\text { - Gruta do Fogo }(9,81) \\
\text { - Gruta da Santa }(9,83)\end{array}$ & - & $\begin{array}{c}\text { - Gruta Mãozinha }(10,54) \\
\text { - Mirante da Anta }(10,59) \\
\text { - Cachoeira do Mirante }(10,65) \\
\text { - Cachoeira da Água Comprida }(11,12) \\
\text { - Gruta Jane Mansfield }(11,13) \\
\text { - Toca dos Meninos }(11,17) \\
\text { - Gruta Luminosa (entorno) }(11,25) \\
\text { - Gruta do Fendão }(11,66) \\
\text { - Gruta Colorida }(11,69) \\
\text { - Cachoeira do Arcão (entorno) }(12,25) \\
\text { - Gruta dos Paiva (entorno) }(13,33)\end{array}$ \\
\hline $\mathbf{R P}$ & $\begin{array}{c}\text { - Gruta do Cipó }(6,57) \\
\text { - Gruta do Tatu }(7,44) \\
\text { - Gruta do Minotauro }(7,65) \\
\text { - Gruta do Fogo }(9,91) \\
\text { - Gruta da Santa }(9,92)\end{array}$ & - Gruta da Mãozinha $(10,08)$ & $\begin{array}{c}\text { - Cachoeira do Mirante }(10,64) \\
\text { - Gruta Luminosa (entorno) }(10,68) \\
\text { - Gruta do Fendão }(10,75) \\
\text { - Mirante da Anta }(11,10) \\
\text { - Gruta Jane Mansfield }(11,22) \\
\text { - Toca dos Meninos }(11,32) \\
\text { - Cachoeira da Água Comprida }(11,40) \\
\text { - Gruta Colorida }(11,97) \\
\text { - Cachoeira do Arcão (entorno) }(12,60) \\
\text { - Gruta dos Paiva (entorno) }(14,24)\end{array}$ \\
\hline
\end{tabular}

Figura 16 - Classificação dos geossítios em relação ao alcance de sua relevância (nacional, regional, local) pelos rankings Tradicional (RT) e Proposto (RP).

\begin{tabular}{|c|c|c|}
\hline Área Cárstica & Geossítios analisados & Níveis e Percentuais de Relevância \\
\hline $\begin{array}{l}\text { Chapada Diamantina } \\
\text { (Pereira, 2010) }\end{array}$ & 40 & $\begin{array}{c}\text { Internacional: } 8(20,0 \%) \\
\text { Nacional: } 9(22,5 \%) \\
\text { Regional: } 13(32,5 \%) \\
\text { Local: } 10(25 \%)\end{array}$ \\
\hline $\begin{array}{c}\text { PETAR } \\
\text { (Ferreira, 2014) }\end{array}$ & 19 & $\begin{array}{l}\text { Internacional: } 1(0,5) \\
\text { Nacional: } 13(68,5 \%) \\
\text { Regional: } 5(31 \%) \\
\text { Local: } 0(0 \%)\end{array}$ \\
\hline $\begin{array}{c}\text { PEI } \\
\text { (Dados da pesquisa, RP) }\end{array}$ & 16 & $\begin{array}{l}\text { Internacional: } 0(0 \%) \\
\text { Nacional: } 10(62,5 \%) \\
\text { Regional: } 1(6,25 \%) \\
\text { Local: } 5(31,25 \%)\end{array}$ \\
\hline
\end{tabular}

Figura 17 - Comparação dos resultados de relevância entre as áreas cársticas da Chapada Diamantina, PETAR e PEI.

Os resultados da figura 17 evidenciam que a região do PEI deveria ser alvo de ações e iniciativas voltadas para ampliar a valorização de sua geodiversidade. Dentre as ações possíveis, destaca-se a descrição de seus geossítios tal como feita para as regiões cársticas do PETAR (e.g. Karmann \& Ferrari, 2002) e da Chapada Diamantina (e.g. Berbert-Born \& Karmann, 2002; Pedreira, 2002; Laureano Cruz Jr., 2002) e sua inclusão na proposta de geoparque já 
existente para a região do Alto Ribeira (Theodorovicz, 2014). Outro destaque importante, pela comparação dos resultados obtidos, é a necessidade da produção e instalação de painéis interpretativos sobre a geodiversidade, em todos os geossítios do PEI.

\section{CONCLUSÕES}

O presente artigo apresentou os resultados da caracterização, quantificação e classificação dos geossítios do PEI. Foram apresentados os resultados dos 23 parâmetros que compõem o Vi, Vci, Vtur, Vug e Ved para os 16 geossítios cársticos analisados, os quais foram analisados e comparados em relação à média geral calculada.

Tradicionalmente, os trabalhos sobre classificação de geossítios não têm enfatizado com o mesmo cuidado e atenção o uso da geodiversidade em função das matrizes curriculares da educação no Brasil. Assim, a proposta ora apresentada adaptou os métodos vigentes, incluindo também os conteúdos curriculares da educação formal na análise do patrimônio geoambiental.

Em relação aos resultados do Valor de Uso Turístico, estes apontam que os geossítios acima da média possuem uma acessibilidade fácil em relação a sede administrativa, como é o caso da gruta do Fogo, Colorida e cachoeira do Mirante. Mesmo a gruta do Fendão, mais distante da sede, pode ser considerada de acesso fácil, considerando que seu público-alvo são os turistas de aventura.

Em relação ao novo valor proposto, o de Uso Turístico-Educacional (VUTE), nota-se que os geossítios que obtiveram pontuações no Vci, Vtur e Ved na média ou acima dela apresentaram um VUTE acima da média, representando a correlação entre estes parâmetros. No entanto, nota-se que as Geociências não são exploradas e divulgadas de forma adequada, bem como as informações sobre o contexto geoambiental não são apresentadas nos painéis informativos existentes. É importante que a geologia e outras áreas das geociências sejam adequadamente divulgadas, por meio de ações concretas, como a confecção de folhetos e painéis geoturísticos, nos geossítios inventariados. Outra ação proposta é a realização de cursos de capacitação para os guias locais com um enfoque sobre as temáticas de geoconservação. Tais ações se justificam pela existência de geossítios de relevância regional e nacional no PEI, o que também é base para a adoção de estratégias geoconservacionistas, como a descrição formal dos geossítios e sua inclusão na proposta de geoparque existente para a região do Alto Ribeira. Ressalta-se também a necessidade de realização de pesquisas complementares, para que outros geossítios possam ser identificados e caracterizados, revelando outros aspectos sobre a geodiversidade do PEI e seu entorno.

Por fim, conclui-se que a presente pesquisa também contribuiu para os avanços nos estudos da geodiversidade e da geoconservação, ao demonstrar que: a) biodiversidade, geodiversidade e sociodiversidade se complementam na perspectiva da conservação; e b) que em casos como os do PEI, o valor turístico não deve ser dissociado do uso educacional, em função das práticas existentes e das possibilidades futuras para sua ampliação e complementação com outros conteúdos e a aplicação em diferentes níveis de ensino.

\section{REFERÊNCIAS}

ALMEIDA, F.F.M. O Cráton do São Francisco. Revista Brasileira de Geociências, v. 7, p. 349-364, 1977.

ARAÚJO, E.L.S. Geoturismo: conceptualização, implementação e exemplo de aplicação ao Vale do Rio Douro no Setor Porto-Pinhão. 2005. 219 f. Dissertação (Mestrado em Ciências do Ambiente) - Escola de Ciências, Universidade do Minho, Minho, 2005.

BEARD, C.; SWARBROOKE, J.; LECKIE, S.; POMFRET, G. Turismo de Aventura: conceitos e estudos de caso. Rio de Janeiro: Elsevier, 2003

BORN, M. \& KARMANN, I. Lapa dos Brejões - Vereda Romão Gramacho, Chapada Diamantina, BA. In: SCHOBBENHAUS, C.; CAMPOS, D.A.; QUEIROZ, E.T.; WINGE, M.; BERBERT-BORN, M. (Ed.). Sítios Geológicos e Palentológicos do Brasil. Brasília: DNPM; CPRM: Comissão Brasileira de Sítios Geológicos e Paleobiológicos - SIGEP, 2002. p. 469-479.

BRASIL, Decreto n. 4146, de 04 de março de 1942. Dispõe
Sobre a Proteção dos Depósitos Fossilíferos. Disponível em: <http://legislacao.planalto.gov.br/legisla/legislacao.nsf/Viw_I dentificacao/DEL\%204.146-1942?OpenDocument>. Acesso em: 03 out. 2018.

BRASIL, Decreto n. 9985, de18 de julho de 2000. Sistema Nacional de Unidades de Conservação da Natureza. Disponível em: <https://www.planalto.gov.br/ccivil 03/leis/19985.html>. Acesso em: 08 out. 2015.

BRASIL. Ciências da natureza, matemática e suas tecnologias / Secretaria de Educação Básica. Brasília: Ministério da Educação, Secretaria de Educação Básica. Orientações curriculares para o ensino médio, 2006b. v. 2. 135 p.

BRASIL. Conhecimentos de Sociologia. Brasília: Ministério da Educação, Secretaria de Educação Básica. Orientações curriculares para o ensino médio, 2006c. v. 3.133 p.

BRASIL. Constituição (1988). Constituição da República Federativa do Brasil. Brasília, DF: Senado Federal: Centro Gráfico, 1988. 292 p. 
BRASIL. Constituição (1988). Constituição da República Federativa do Brasil. Brasília, DF: Senado Federal: Centro Gráfico, 1988. 292 p.

BRASIL. Linguagens, códigos e suas tecnologias / Secretaria de Educação Básica. Brasília: Ministério da Educação, Secretaria de Educação Básica. Orientações curriculares para o ensino médio, 2006a. v. 1.239 p.

BRASIL. Ministério da Educação. Base Nacional Comum Curricular. Proposta preliminar. Brasília: MEC, 2016. Disponível

<http://basenacionalcomum.mec.gov.br/documentos/bncc-

2versao.revista.pdf $>$ Acesso em: 20 dez. 2017.

BRILHA, J. Inventory and Quantitative Assessment of Geosites and Geodiversity Sites: a Review. Geoheritage, v. 8, n. 2, p. 119-134, 2016.

BRILHA, J. Patrimônio Geológico e Geoconservação: A Conservação da Natureza na sua Vertente Geológica. Palimage, 2005, 183 p.

CAMPANHA, G.A.C. \& SADOWSKI, G.R. Tectonics of the Southern Portion of the Ribeira Belt (Apiaí Domain). Precambrian Research, v. 98, n. 1, p. 31-51, 1999.

CAMPANHA, G.A.C. O papel do sistema de zonas de cisalhamento transcorrentes na configuração da porção meridional da Faixa Ribeira. São Paulo, 2002. 105 p. Tese (Livre-Docência), Instituto de Geociências, Universidade de

CAMPANHA, G.A.C.; BISTRICHI, C.A.; ALMEIDA, M.A. Considerações sobre a organização litoestratigráfica e evolução tectônica da faixa de dobramentos Apiaí. In: SIMPÓSIO SULBRASILEIRO de GEOLOGIA, 3, 1987, Curitiba. Atas... Curitiba: Sociedade Brasileira de Geologia, 1987, v. 2, p. 725742.

CONSELHO NACIONAL DO MEIO AMBIENTE CONAMA. Resolução CONAMA n ${ }^{\circ} 347$ de 10 de setembro de 2004. Dispõe sobre a proteção do patrimônio espeleológico. Diário Oficial da União, Brasília, ed. 176, seção 1, p. 54,13 set. 2004

CPRM. Companhia de Pesquisa de Recursos Minerais -1997. Sigep: Comissão Brasileira de Sítios Geológicos e Paleobiológicos. Disp. em: http://www.cprm. gov.br/geossit. Acesso 03 jun. 2018.

FALEIROS, Frederico Meira; MORAIS Silvia Maria; COSTA Vicente Sérgio. Geologia e recursos minerais da Folha Apiaí - SG.22-X-B-V, Estado de São Paulo e Paraná, Escala 1:100.000 - São Paulo: CPRM, 2012. 107 p.

FENNEL, D. A. Ecoturismo: uma introdução. São Paulo: Contexto, 2002

FERREIRA, Ana Rita Rodrigues. Patrimônio Geológico no Parque Estadual Turístico do Alto da Ribeira-SP: Inventariação e Qualificação de Geossítios. Dissertação (Mestrado), Universidade Estadual Paulista Júlio de Mesquita Filho, 2014. $110 \mathrm{p}$

FOLLONI, A.P. Objetividade e subjetividade nas Ciências Sociais: introdução às relações interdisciplinares entre Direito e desenvolvimento. Revista do Direito Público. Londrina, 2014. v.9, n.3, p.25-43. Disp.em: < http://www.uel.br/revistas/uel/index.php/direitopub/article/vie wFile/19806/15474 >. Acesso em: 15 jun. 2018.

FORD, D. \& WILLIAMS, P. Karst Geomorfology and Hydrology. Edição Revisada. 2007.

FUNDAÇÃO FLORESTAL. Parque Estadual Intervales: Planos de Manejo Espeleológico Resumo Executivo. São Paulo, 2010. 113 p. Disp. em: <http://fflorestal.sp.gov.br/files/2012/01/PME_PEI_resumo_e xecutivo.pdf> Acesso em: 01 dez. 2015.

FUNDAÇÃO FLORESTAL. Parque Estadual Intervales: Resumo Executivo do Plano de Manejo. São Paulo, 2008. 134 p. Disp. em: <http://fflorestal.sp.gov.br/planos-demanejo/planos-de-manejo-planos-concluidos/>. Acesso em: 01 dez. 2015

GARCIA, M.G.M.; BRILHA, J.; LIMA, F.F. The Inventory of Geological Heritage of the State of São Paulo, Brazil:
Methodological Basis, Results ans Perspectives. Geoheritage, v. 1, p. 1-20, 2017.

GRAY, M. Geodiversity: valuing and conserving abiotic nature. John Wiley and Sons Ltd, Chichester, England. 2004.

HASUI, Y.; CARNEIRO, C.D.R.; COIMBRA, A.M. The Ribeira folded belt. Revista Brasileira de Geociências, v. 5, p. 257266, 1975 .

IUCN. International Union for Conservation of Nature. Disp. em: < https://www.iucn.org/about/union >. Acesso em: 21 nov. 2017.

KARMANN, I. \& FERRARI, J.A. Sítios Espeleológicos - Carste e cavernas do Parque Estadual Turístico do Alto Ribeira (PETAR), SP. In: SCHOBBENHAUS, C.; CAMPOS, D.A.; QUEIROZ, E.T.; WINGE, M.; BERBERT-BORN, M.L.C. (Orgs.) Sítios geológicos e paleontológicos do Brasil. Brasília: DNPM/CPRM - Comissão Brasileira de Sítios Geológicos e Paleobiológicos (SIGEP), 2002. p.401-413.

LAUREANO, F.V. \& CRUZ JR., Francisco Willian da. Grutas de Iraquara (Iraquara, Seabra e Palmeiras), BA. In: SCHOBBENHAUS, C.; CAMPOS, D.A.; QUEIROZ, E.T.; WINGE, M.; BERBERT-BORN, M. (Ed.). Sítios Geológicos e Palentológicos do Brasil. Brasília: DNPM; CPRM: Comissão Brasileira de Sítios Geológicos e Paleobiológicos - SIGEP, 2002. p. 461-468.

LENHARE, B.D. \& SALLUN FILHO, W. Diferenças espeleométricas entre as cavernas do Planalto de Guapiara e Serra de Paranapiacaba, na região do Parque Estadual Intervales (PEI), estado de São Paulo. In: RASTEIRO, M.A.; SALLUN FILHO, W. (orgs.). In: CONGRESSO BRASILEIRO DE ESPELEOLOGIA, 33, 2015. Eldorado. Anais...Campinas: SBE, 2015. p.495-503. Disp. em: <http://www.cavernas.org.br/anais33cbe/33cbe_495-503.pdf>. Acesso em: 14 Jan. 2018.

LOBO, H.A.S. \& BOGGIANI, P.C. Cavernas como patrimônio geológico. Boletim Paranaense de Geociências, v. 70, p. 190 $-199,2013$.

LOBO, H.A.S.; BORSANELLI, F.A.; CAMARGO, T.C.R. Conservação do patrimônio geoambiental na região de Sorocaba, SP: perspectivas e possibilidades. In: SILVA, Carlos Henrique Costa da; SILVA, Edelci Nunes da. Chão da Terra: olhares, reflexões e perspectivas geográficas de sorocaba. Curitiba: CRV, 2016. p. 187-207.

MARINHO, M. A. Resumo Executivo de Plano de Manejo, 2008. Disp. em: <http://fflorestal.sp.gov.br/planos-demanejo/planos-de-manejo-planos-concluidos/>. Acesso em: 08 out. 2015

MINISTÉRIO DO MEIO AMBIENTE. Diretrizes para visitação em unidades de conservação. Secretaria de Biodiversidade e Florestas. Departamento de Áreas Protegidas. Brasília: Ministério do Meio Ambiente, 2006. p. 72.

MONTEIRO, C.A.F. A dinâmica climática e as chuvas no estado de São Paulo: estudo geográfico sob a forma de atlas. São Paulo, 1973. 129 p. Instituto de Geografia da Universidade de São Paulo,

NEIMAN, Z. A educação ambiental através do contato dirigido com a natureza. 2007. 138 f. Tese (Doutorado em Psicologia) - Instituto de Psicologia, Universidade de São Paulo, São Paulo. 2007, 234p.

NUNES, E.; ARAGÃO, T.M.F.M.; STARCK, C. Visitação e análise de acessibilidade a três parques estaduais do Vale Ribeira: Parque Estadual Turístico do Alto Ribeira (PETAR), Parque Estadual de Intervales (PEI) e Parque Estadual Caverna do Diabo (PECD). In: RASTEIRO, M.A.; SALLUN FILHO, W. (orgs.) CONGRESSO BRASILEIRO DE ESPELEOLOGIA, 33, 2015. Eldorado. Anais... Campinas: SBE, 2015. p.735-745. Disp. em: <http://www.cavernas.org.br/anais33cbe/33cbe_735-745.pdf> Acesso em: 25 set. 2017.

NURIT, B. Conservação da Biodiversidade em Áreas Protegidas. FGV, 2006. 176p. 
PEDREIRA, A.J. Serra do Sincorá, Chapada Diamantina, BA. In: SCHOBBENHAUS, C.; CAMPOS, D.A.; QUEIROZ, E.T.; WINGE, M.; BERBERT-BORN, M. (Ed.). Sítios Geológicos e Palentológicos do Brasil. Brasília: DNPM; CPRM: Comissão Brasileira de Sítios Geológicos e Paleobiológicos - SIGEP, 2002. p. 187-194

PEREIRA, R.D.A. Geoconservação e desenvolvimento sustentável na Chapada Diamantina (Bahia-Brasil). Tese 9Doutorado em Geologia), Escola de Ciências, Universidade do Minho, Braga (Portugal), 2010,269 p.

ROSS, J.L.S. \& MOROZ, I.C. MAPA GEOMORFOLÓGICO DO ESTADO DE SÃO PAULO. Revista do Departamento de Geografia, São Paulo, v. 10, p. 41-58, nov. 2011. ISSN 2236-2878. Disp. em: < http://www.revistas.usp.br/rdg/article/view/53703 >. Acesso em: 14 jan. 2018.

SALLUN, A. \& SALLUN FILHO, W. Geologia em planos de manejo: subsídios para zoneamento ambiental do Parque Estadual Intervales, estado de São Paulo, Brasil. Rem: Revista Geociências. São Paulo, v. 28, n. 1, p. 91-107, 2009. Disp. em: $<$ http://www.revistageociencias.com.br/geocienciasarquivos/28_1/Art\%2008_Sallun.pdf $>$. Acesso em jun. 2017.

SÃO PAULO. Plano de Manejo do Parque Estadual Intervales. São Paulo, 2009

SHARPLES, C. Concepts and principles of geoconservation. Australia: Tasmanian Parks \& Wildlife Service, 2002. 2p. Disp.em:

<http://dpipwe.tas.gov.au/Documents/geoconservation.pdf>. Acesso em: 20 nov. 2015.
SISTEMA AMBIEnTAL PAUlista. Plano de Manejo Resumo Executivo. São Paulo, aprovação pela deliberação CONSEMA n ${ }^{\circ} 08$ de 18 de fevereiro de 2009. 134 p. Disp. em: $<$ http://fflorestal.sp.gov.br/planos-de-manejo/planos-demanejo-planos-concluidos/plano-de-manejo-pe-intervales/>. Acesso em: 13 out. 2016.

SISTEMA AMBIENTAL PAULISTA. Projeto de Desenvolvimento do Ecoturismo na Região da Mata Atlântica. São Paulo, 2013, 82 p. Disp. em: <http://www.ambiente.sp.gov.br/ecoturismo/files/2013/10/Liv roEcoturismo2013.pdf>. Acesso em 15 out. 2016.

THEODOROVICZ, Antônio. Geoparque Alto Vale do Ribeira: Projeto. Brasília: CPRM, 2014, 79 p. Disp. em: http://rigeo.cprm.gov.br/jspui/handle/doc/15063>. Acesso em 27 mar. 2020

UNESCO. Ciências Naturais. Disp.em: $<$ http://www.unesco.org/new/pt/brasilia/naturalsciences/environment/natural-heritage/>. Acesso em: 30 ago. 2017.

UNESCO. Representação no Brasil. Disp.em: $<$ https://nacoesunidas.org/agencia/unesco/>. Acesso em: 15 jun. 2018.
Submetido em 4 de julho de 2018 Aceito em 30 de março 2020 